\title{
Modelling Rainfall Series in North Central Nigeria: A Comparative Study of Box-Jenkins and State Space Model Approaches
}

\section{${ }^{1 *}$ Adejumo Oluwasegun Agbailu, ${ }^{2}$ Asemota Omorogbe Joseph, ${ }^{3}$ Yahaya Haruna Umar}

\author{
${ }^{1,3}$ Department of Statistics, University of Abuja. \\ ${ }^{2}$ National Institute for Legislative Studies, National Assembly, Nigeria. \\ *Corresponding Author: olushegzy006@gmail.com
}

Received: $06^{\text {th }}$ November $2020 /$ Revised: $8^{\text {th }}$ December $2020 /$ Published: $15^{\text {th }}$ December 2020

CIAppstat-SL2020

\begin{abstract}
This study aims at examining the performances of Box-Jenkins (BJ) and State Space (SS) modelling approaches, evidence from rainfall series of the North Central part of Nigeria. The study utilized monthly rainfall series of five North Central states of the country covering the period January 1961 to July 2019. This study employed the following methodologies: The Augmented Dickey-Fuller test for the non-seasonal stationarity check; HEGY test for the seasonal stationarity check; the Seasonal AutoRegressive Integrated Moving Average modelling strategy of Box-Jenkins; and the State Space Local Level modelling with Seasonality. Among the 20 candidate BJ models estimated for each of the five states rainfall series, the study returned $\operatorname{SARIMA}(4,0,4)(1,0,0)_{12}, \quad \operatorname{SARIMA}(3,0,3)(2,0,0)_{12}, \quad \operatorname{SARIMA}(2,0,3)(1,0,0)_{12}$, $\operatorname{SARIMA}(2,0,4)(1,0,0)_{12}$ and SARIMA(4,0,2)(2,0,0) 12 as the most parsimonious BJ models for Benue, Niger, Kogi, Kwara and Federal Capital Territory (FCT) states respectively. Also, using the SS approach the study fitted Local Level Models with stochastic seasonality for each of the state rainfall series and were labelled SSBER, SSNIR, SSKOR, SSKWR and SSFCR for Benue, Niger, Kogi, Kwara and FCT states respectively. The forecasting performances of the most parsimonious SARIMA models and State Space Local Level Model with stochastic seasonality were examined. From the forecasts evaluation results, the RMSE, MAE, Theil's U criteria and average of the three loss functions indicate that the state space local level model with seasonality outperformed the BJ models (SARIMA). In conclusion, SS models returned as more robust models compared to any BJ models (SARIMAs). Thus, it is evident that SS model is a noble intervention capable of modelling different features
\end{abstract}


characteristic in a series such as trend and seasonality. The study therefore recommends the adoption of state space modelling approach based on the ability of the approach to accommodate distinct features instead of differencing (i.e. eliminating trend and seasonality).

Keywords: Climate, Rainfall, Time Series, State Space, Box-Jenkins, SARIMA.

\section{Introduction}

Recent increased flood risk is acknowledged as the most imperious sectorial threat from climate change in many parts of the world including Nigeria, which has provoked public debate on the apparent increased frequency of extreme. Several studies have cited extreme rainfall to be the key cause of flood globally. Such studies include [5], [30], [23], and [26] to mention but few. Reference [23] and [25] recognized the characteristics of extreme rainfall that are associated with flood frequency to include duration, intensity, frequency, seasonality, variability, trend and fluctuation. Quite a lot of studies have been conducted in the modelling of rainfall pattern in various regions of the world especially in Nigeria using different methodologies. Debatably, Box-Jenkins (BJ) approach specifically the Seasonal Autoregressive Integrated Moving Average (SARIMA) is one of the common methods most researchers used in modelling rainfall patterns such as [11], [12], [16], [20], [21], [22] and many others. For instance, [8] in their study found out that SARIMA model outperformed the SARIMA-X and autoregressive distributed lag model. They recommended that SARIMA model should be adopted when dealing with seasonality. In addition, [6] presented a time series analysis and forecasting of monthly maximum temperatures in south eastern Nigeria. Their study investigated the ability of Autoregressive (AR), Moving Average (MA), Autoregressive Moving Average (ARMA), Autoregressive Integrated Moving Average (ARIMA), and SARIMA models in forecasting monthly rainfall. Their result showed that in $33 \%$ of data $\operatorname{MA}(2)$, in $22 \%$ of data $\operatorname{AR}(1)$ and $\operatorname{ARMA}(2,1)$ and in $11.11 \%$ of data $\operatorname{MA}(1)$ and $\operatorname{ARIMA}(1,1,2)$ had the best performance in monthly rainfall forecasting. Also, [1] examined SARIMA modelling and forecasting of monthly rainfall in the Brong Ahafo Region of Ghana. SARIMA $(0,0,0)(1,1,1)_{12}$, with an AIC score of 8.985894, was identified as an appropriate model for predicting monthly aver-age rainfall figures for the Brong Ahafo Region of Ghana.

Furthermore, [16] studied monthly rainfall over Dibrugarh, Assam, using SARIMA approach and they investigated found that $\operatorname{SARIMA}(0,0,0)(0,1,1)_{12}$ model is suitable for the given data set. Reference [20] forecast daily meteorological time series using ARIMA and regression models. In their forecasting they used the 
methods of the BJ and Holt- Winters SARIMA, the ARIMA with external regressors in the form of Fourier terms and the time series regression, including trend and seasonality components methodology with R software.

Nevertheless, in recent years, there are growing concerns among time series researchers ([28] and [3]) that BJ models may not always lead to accurate forecasting especially in economic and business applications where the level of randomness is high and the constancy of patterns or parameters cannot be guaranteed. The state space method of time series analysis has numerous advantages over the BJ models [3]. As state space method is seen to be more wide-ranging and is based on the modelling of all the observable data. The different features characteristic in a series such as trend, seasonal, cycle, explanatory variables and interventions can be modelled separately before being put together in the state space model [3]. Also, the assumption of stationarity is not desirable in state space model. In contrast, the BJ model is based on the removal or elimination of trend and seasonality by differencing until stationarity is accomplished. Reference [9] stated that differencing time series in order to eliminate trend and seasonality may pose a problem in econometric applications where knowledge of the components is desired. Reference [9] discuss more on the relative merit of state space models over the celebrated BJ models. Thus, based on the foregoing this study is proposed to examine the performances of the BJ and state space modelling approaches using the rainfall series of the following North Central states of Nigeria; Benue, Niger, Kogi, Kwara and Federal Capital Territory (FCT).

\section{Study Area}

The North-Central part of Nigeria comprises of six states and the FCT with this region mostly known for the production of crops and livestock which contribute greatly to the economy of the country (see Figure 1). Howbeit, this research is limited to five states based on rainfall data availability as at the time of the research. The five states are namely Benue (nickname; Food Basket of the Nation), Niger (nickname; The Power State), Kogi (nickname; Confluence State), Kwara (nickname; State of Harmony) and FCT. 


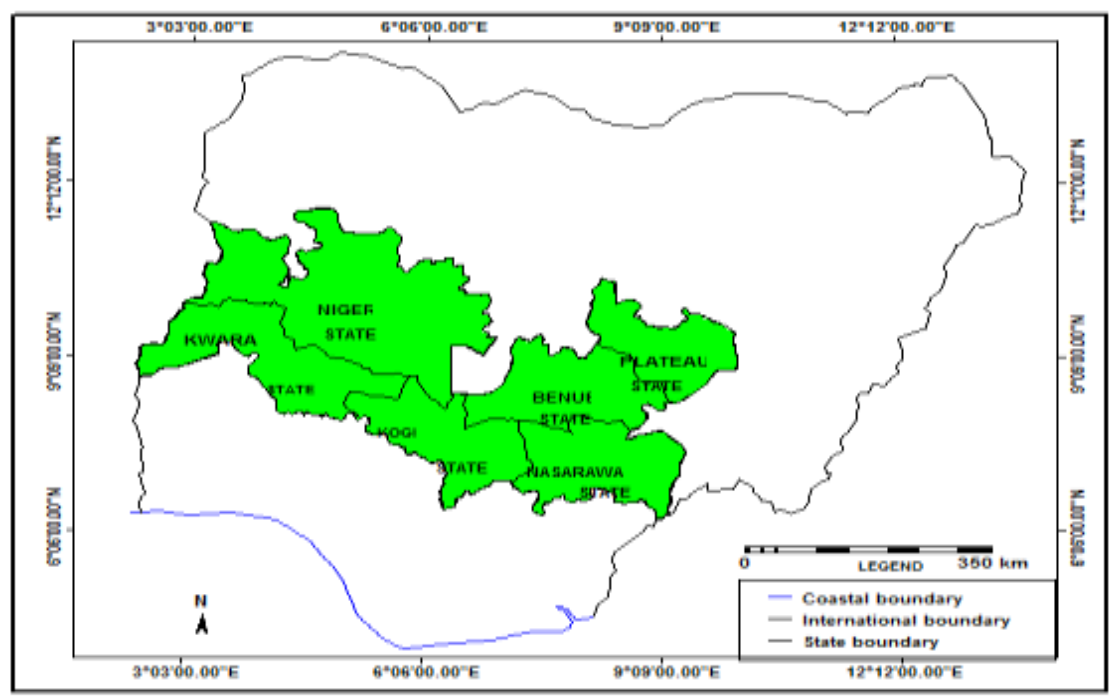

Figure 1. Map of Nigeria.

\section{A. Benue State}

Benue State is peopled predominantly by the Tiv, Idoma and Igede peoples, who speak Tiv, Idoma, and Igede languages respectively. Its capital is Makurdi. Benue is known to be the "Food Basket of the Nation" because is rich in agricultural products; popularly grown crops are sweet potatoes, cassava, soya bean, guinea corn, flax, yams, sesame, rice, and groundnuts, Palm Tree. Benue State is named after the Benue River and was formed from the former Benue-Plateau State in 1976, along with Igala and some part of Kwara State. In 1991 some areas of Benue state (mostly Igala area), along with areas in Kwara State, were carved out to become part of the new Kogi State. Igbo people are found in the boundary areas like the Obi, Oju and many others.

\section{B. Niger State}

Niger state is bounded to the south by the Niger River which also is bounded by the states of Kebbi and Zamfara to the north, Kaduna to the north and northeast, Kogi to the southeast, and Kwara to the south. The Abuja Federal Capital Territory is on Niger state's eastern border, and the Republic of Benin is its western border. The landscape consists mostly of wooded savannas and includes the floodplains of the Kaduna River. Niger state is populated mainly by the Nupe people in the south, the Gwari in the east, the Busa in the west, and Kamberi (Kambari), Hausa, Fulani, Kamuku, and Dakarki (Dakarawa) in the north. Islam is the predominant religion. Most of the inhabitants are engaged in farming. Cotton, shea nuts, yams, and peanuts (groundnuts) are cultivated both for export and for domestic consumption. Sorghum, millet, cowpeas, corn (maize), tobacco, palm oil and kernels, kola nuts, sugarcane, 
and fish are also important in local trade. Paddy rice is widely grown as a cash crop in the floodplains of the Niger and Kaduna rivers, especially in the area around Bida. Cattle, goats, sheep, chickens, and guinea fowl are raised for meat. Pigs are raised around Minna for sale to southern Nigeria.

\section{Kogi State}

Kogi (the confluence state) is a state in the central region (Middle-Belt) of Nigeria. It is popularly called the Confluence State because of the confluence of River Niger and River Benue at its capital, Lokoja, which is the first administrative capital of modernday Nigeria. Agriculture is the key part of the state economy with casting (fishing) in the riverine areas like Lokoja, Idah, Baji,etc., and the state also has coal, petroleum, steel and other mineral industries. The main ethnic groups are Igala, Ebira and Okun.

\section{Kwara State}

Kwara is a state in Northern Nigeria with its capital, Ilorin. Kwara is found within the North Central geopolitical zone, frequently referred to as the Middle Belt. The primary ethnic group is Yoruba, with significant Nupe, Bariba and Fulani minorities. Kwara state lies within a region described as tropical climate and are characterized by double rainfall maxima and has tropical wet and dry climate [24]. Each season lasts for about six months. Kwara State is a summer rainfall area, with an annual rainfall range of $1000 \mathrm{~mm}$ to $1500 \mathrm{~mm}$. The rainy season begins in March and lasts until early September, while the dry season begins in early October and ends in March [2].

Temperature is homogeneously high and ranges between $250 \mathrm{C}$ and $300 \mathrm{C}$ in the wet season throughout the season except in July - August when the clouding of the sky prevents direct insolation (heatstroke) while in the dry season it ranges between $330 \mathrm{C}$ to $34 \mathrm{oC}$. Relative humidity at Ilorin in the wet season is between 75 to $80 \%$ while in the dry season it is about $65 \%$. The daytimes are sunny and the sun shines brightly for about 6.5 to 7.7 hours daily from November to May (NBS, 2009). Agriculture is the focal source of the economy and the principal cash crops which are: cotton, cocoa, coffee, Kolanut, tobacco, beniseed and palm produce. As well Kwara state has abundant mineral resources; these are Gold, limestone, marble, feldspar, clay, kaolin, quartz and granite rocks.

\section{E. Abuja FCT}

Abuja is located in the center of Nigeria and has a land area of 8,000 square Kilometers. It is bounded on the north by Kaduna state, on the west by Niger state, 
on the east and south-east by Nasarawa state and on the south-west by Kogi state. It falls within latitude $745^{\prime}$ and 7 39'. One beautiful feature about Abuja which it derives from its central location is that it shares the savannah grass with the north. And the overall effect of this is that Abuja has rich soil for Agriculture and enjoys an equable climate that is neither too hot nor too cold all year round. The FCT experiences two weather conditions in the year. These are the rainy season which begins around March and runs through October, the dry season (usually characterized by bright sunshine) which begins from October and ends in March. Within these periods, there is a brief period of harmattan occasioned by the north east trade wind, with a resultant dusty haze and intense coldness and dryness. Nevertheless, the high altitude and undulating terrain of the FCT act as a modulating influence which makes the weather always clement.

\section{Research Methodology}

\subsection{Augmented Dickey-Fuller (Non-seasonal) Test}

In the statistical analysis of time series with obvious seasonality, it has become a tradition that the non-seasonal unit root hypothesis is first tested for each of the variables to ascertain the order of non-seasonal integration of the variable [4]. We employ the Augmented Dickey-Fuller (ADF) test based on the following regression:

$$
\Delta y_{t}=\varphi+\beta_{t}+\alpha y_{t-1}+\sum_{i=1}^{k} d_{i} \Delta y_{t-1}+\varepsilon_{t}
$$

Where $u_{t}$ is a white noise error term and $\Delta y_{t-1}=y_{t-1}-y_{t-2}, \Delta y_{t-2}=y_{t-2}-$ $y_{t-3}$, etc. Equation 1 tests the null hypothesis of a unit root (i.e. non-seasonal not stationary) against a trend stationary alternative.

What is then tested is the null hypothesis of a unit root i.e. $\rho=1$ against the alternative hypothesis of stationarity that is $/ \rho /<1$. The test statistic (t-type) that is used is $D F_{\tau}=\frac{\widehat{\boldsymbol{\rho}}-\mathbf{1}}{\boldsymbol{S} \boldsymbol{E}(\widehat{\boldsymbol{\rho}})} \quad$ where the estimated value of the t-statistic would be compared to the value of the related critical value of the Dickey-Fuller test.

\subsection{HEGY Test}

To carry out a seasonal unit root test at any frequency, we begin with the decomposition theory of the polynomial $\varphi(B)$ by following the decomposition technique in [14]. Let $y_{t}$ be a univariate time series satisfying a $\mathrm{P}^{\text {th }}$-order autoregressive model;

$$
\varphi(B) y_{t}=\varepsilon_{t}
$$

where $\varphi(B)$ is the autoregressive polynomial with order $\mathrm{P}, S \leq P \leq \infty$ and $\varepsilon_{t} \sim \operatorname{iid}\left(0, \sigma^{2}\right)$. 
Consider the autoregressive polynomial $\varphi(u)$ in the model (2). Assume that $\varphi(u)$ is expanded at the $S$ unit roots $u_{m}=\cos \theta_{m}+i \sin \theta_{m}, \mathrm{~m}=1, \ldots, S$. Then $\varphi(u)$ in (3.2) can be decomposed as;

$$
\varphi(u)=\sum_{m=1}^{S} \tau_{m} \varphi_{m}(u)+\varphi^{*}(u)\left(1-u^{s}\right)
$$

where $\varphi_{m}(u)=\frac{u}{u_{m}} \prod_{j=1, j \neq m}^{S}\left(1-\frac{u}{u_{j}}\right)$ for $\mathrm{m}=1, \ldots, \mathrm{S}$ and $\varphi^{*}(B)$ is a remainder polynomial with order $P-S$. Consider a univariate seasonal time series $y_{t}$ with frequency $S$. Assume $y_{t}$ satisfies the autoregressive model (2) then model (2) contains the following;

$$
\varphi^{*}(B)\left(1-B^{S}\right) y_{t}=\sum_{m=1}^{S} \rho_{m} x_{m, t}+\varepsilon_{t}
$$

where $\varepsilon_{t} \sim \operatorname{iid}\left(0, \sigma^{2}\right)$ and $x_{m, t}=\varsigma_{m}(B) y_{t}$ whereas

$$
\varsigma_{m}(B)=\left\{\begin{array}{cc}
\sum_{j=1}^{S} \cos \left(j \theta_{m}\right) B^{j} & m=1, m_{\text {even }}=\pi \\
\sum_{j=1}^{S} \sin \left(j \theta_{m}\right) B^{j} & m=m_{\text {odd }}
\end{array}\right\}
$$

The model (5) is used for testing the seasonal unit roots of $y_{t}$ in (2).

Testing for seasonal unit root; for the polynomial $\varphi(z)$ in (2), $\varphi(z)=0$ has a unit root at frequency $\theta_{m}$ if and only if the parameter of the related regressor $\boldsymbol{x}_{\boldsymbol{m}, \boldsymbol{t}}$ in (4) equals to 0 . Hence, testing for presence of seasonal unit roots for data at frequency $\theta_{m}$ are equivalent to test if the corresponding parameters $\rho_{m}$ of $x_{m, t}$ in (4) are zero.

\subsection{Multiplicative SARIMA $(\mathbf{p , d}, \mathbf{q})(\mathbf{P}, \mathrm{D}, \mathrm{Q})_{\mathrm{s}}$ Modeling Strategy}

The seasonal autoregressive integrated moving average (SARIMA) model is applied to the five states rainfall time series $\left(y_{t}\right)$ earlier mentioned with the following expression (Brockwell and Davis, 1991).

$$
\Phi\left(L^{s}\right) \emptyset(L) \Delta^{d} \Delta_{s}^{D} y_{t}=\theta_{0}+\Theta\left(L^{s}\right) \theta(L) \varepsilon_{t}
$$

The models are therefore specified as $\operatorname{SARIMA}(\mathrm{p}, \mathrm{d}, \mathrm{q})(\mathrm{P}, \mathrm{D}, \mathrm{Q})_{\mathrm{s}}$, where $\mathrm{s}$ is the seasonal length, for instance $\mathrm{s}=12$ for monthly data, $\mathrm{L}$ is the lag operator and $\varepsilon_{t}$ is Gaussian white-noise process with mean zero and variance $\sigma^{2}$. The difference operator is $\Delta^{d}$ where $d$ postulates the order of differencing for $y_{t}$ to be stationary $y_{t}^{*}$ similarly the seasonal difference operator is $\Delta_{s}^{D}$ where $D$ is the order of seasonal differencing for $y_{t}$ to be stationary.

$y_{t}^{*}=(1-L)^{d}\left(1-L^{S}\right)_{y_{t}}^{D}$

Furthermore $\emptyset(\mathrm{L})$ and $\theta(\mathrm{L})$ are defined as follow; polynomials in the lag operator.

$$
\begin{aligned}
& \emptyset(L)=1-\emptyset_{1} L-\cdots-\emptyset_{p} L^{p} \\
& \theta(L)=1+\theta_{1} L+\cdots-\theta_{q} L^{q}
\end{aligned}
$$


The seasonal polynomials $\Phi\left(L^{S}\right)$ and $\Theta\left(L^{S}\right)$ in the lag operator can be stated as follows

$$
\begin{aligned}
& \Phi\left(L^{S}\right)=1-\Phi L^{S}-\cdots-\Phi_{p} L^{P S} \\
& \Theta\left(L^{S}\right)=1+\Theta_{1} L^{S}+\cdots-\Theta_{q} L^{Q S}
\end{aligned}
$$

$\operatorname{SARIMA}(\mathrm{p}, \mathrm{d}, \mathrm{q})(\mathrm{P}, \mathrm{D}, \mathrm{Q})_{\mathrm{s}}$ for $y_{t}$ can be seen as a special form of the equivalent representation of $y_{t}^{*}$ as an $\mathrm{ARMA}(\mathrm{p}+\mathrm{sP}, \mathrm{q}+\mathrm{sQ})$ written as

$$
\varnothing(L)^{*} y_{t}^{*}=\theta_{0}+\theta(L)^{*} \varepsilon_{t}
$$

AR part $\left[\varnothing(L)^{*}\right]$ in this model (12) is derived by multiplying the autoregressive lag polynomials $\varnothing(\mathrm{L})$ and $\Phi\left(L^{S}\right)$ from $\varphi^{*}(B)\left(1-B^{S}\right) y_{t}=\sum_{m=1}^{S} \rho_{m} x_{m, t}+\varepsilon_{t}$; where $\varepsilon_{t} \sim i i d\left(0, \sigma^{2}\right)$ and $x_{m, t}=\varsigma_{m}(B) y_{t}$ and (6), whereas;

$\varsigma_{m}(B)=\left\{\begin{array}{cc}\sum_{j=1}^{S} \cos \left(j \theta_{m}\right) B^{j} & m=1, m_{\text {even }}=\pi \\ \sum_{j=1}^{S} \sin \left(j \theta_{m}\right) B^{j} & m=m_{\text {odd }}\end{array}\right\}$

Thus, the AR part is;

$\emptyset(L)^{*}=\varnothing(L) \Phi\left(L^{S}\right)=\left(1-\phi_{1} L-\cdots-\phi_{p} L^{p}\right)\left(1-\Phi_{1} L^{S}-\cdots-\Phi_{p} L^{P S}\right)$

Similarly, for the MA part $\left[\theta(L)^{*}\right]$ is implied with the moving average lag polynomials $\theta(L)$ and $\Theta\left(L^{S}\right)$ which follow from (13) and (7), hence is

$$
\theta(L)^{*}=\theta(L) \Theta\left(L^{S}\right)=\left(1+\theta_{1} L+\cdots-\theta_{q} L^{q}\right)\left(1+\Theta_{1} L^{S}+\cdots-\Theta_{p} L^{Q s}\right)
$$

\subsection{State Space Model (SSM)}

State space model (SSM) is referred to a class of probabilistic graphical model [19] that describes the probabilistic dependence between the latent state variable and the observed measurement. The state can be either continuous or discrete. The term state space originated in 1960s in the area of control engineering [17]. SSM provides a general framework for analyzing deterministic and stochastic dynamical systems that are measured or observed through a stochastic process. Other terms used to describe SSMs are hidden Markov models (HMMs) [27] and latent process models. The most well studied SSM is the Kalman filter, which defines an optimal algorithm for inferring linear Gaussian systems [31].

According to [7] in a state space analysis, the time series observations are assumed to depend linearly on a state vector that is unobserved and is generated by a stochastically time-varying process (a dynamic system). The state space model for the $n$-dimensional observation sequence $y_{1}, y_{2}, \ldots, y_{n}$ is states as.

$$
\begin{aligned}
& y_{t}=Z_{t} \alpha_{t}+\varepsilon_{t}, \quad \varepsilon_{t} \sim N I D\left(0, H_{t}\right) \\
& \alpha_{t+1}=T_{t} \alpha_{t}+R_{t} \zeta_{t}, \zeta_{t} \sim N I D\left(0, Q_{t}\right) \quad \text { where } t=1, \ldots, n
\end{aligned}
$$


where $\alpha_{t}$ is the state vector, $\varepsilon_{t}$ and $\zeta_{t}$ are disturbance vectors and the system matrices $Z_{t}, T_{t}, H_{t}$ and $Q_{t}$ are fixed and known but a selection of elements may depend on an unknown parameter vector. Equation (16) is called the observation or measurement equation, while (17) is called the state or transition equation. The $p \times 1$ observation vector $y_{t}$ contains the $p$ observations at time $t$ and the $m \times 1$ state vector is unobserved. The $p \times l$ irregular vector $\varepsilon_{t}$ has zero mean and $\mathrm{p} \times \mathrm{p}$ variance matrix $H_{t}$.

The $p \times m$ matrix $Z_{t}$ links the observation vector $y_{t}$ with the unobservable state vector $\alpha_{t}$ and may consist of regression variables. The $\mathrm{m} \times \mathrm{m}$ transition matrix $T_{t}$ in (17) determines the dynamic evolution of the state vector. The $r \times 1$ disturbance vector $\zeta_{t}$ for the state vector update has zero mean and $r \times r$ variance matrix $Q_{t}$. The observation and state disturbances $\varepsilon_{t}$ and $\zeta_{t}$ are assumed to be serially independent and independent of each other at all time points. In many standard cases, $\mathrm{r}=\mathrm{m}$ and matrix $R_{t}$ is the identity matrix $\mathrm{Im}$. In other cases, matrix $R_{t}$ is an $\mathrm{m} \times \mathrm{r}$ selection matrix with $r<m$. Although matrix $R_{t}$ can be specified freely, it is often composed of a selection from the first $\mathrm{r}$ columns of the identity matrix $\mathrm{I}_{\mathrm{m}}$. The Initial state distribution is stated as $\alpha_{1} \sim N\left(a_{1}, P_{1}\right)$.

Furthermore, state space methods offer a cohesive approach to a pervasive range of models and techniques: dynamic regression, SARIMA, latent variable models etc. however, this research set to emphasis and concentrates on the SARIMA techniques approach of state space.

To calculate the mean and variance of the unobserved state, given the observations, we use Kalma Filter, a recursive algorithm; the recent best estimate is updated whenever a new observation is gotten. $\alpha_{t}$ is calculated from the observations thus with Kalma Filter;

$$
\begin{aligned}
& u_{t}=y_{t}-Z_{t} a_{t} \\
& F_{t}=Z_{t} P_{t} Z_{t}^{\prime}+H_{t} \\
& K_{t}=T_{t} P_{t} Z_{t}^{\prime} F_{t}^{-\prime} \\
& \alpha_{t+1}=T_{t} a_{t}+K_{t} u_{t} \\
& P_{t+1}=T_{t} P_{t} T_{t}^{\prime}+R_{t} Q_{t} R_{t}^{\prime}-K_{t} F_{t} K_{t}^{\prime}
\end{aligned}
$$

for $t=1, \ldots, n$ and starting with given values for $\alpha_{1}$ and $P_{1}$. Taking note of equation (16) and (17), writing $y_{t}=\left\{y_{1}, y_{2}, \ldots, y_{n}\right]$, we define;

$$
a_{t+1}=E\left(\alpha_{t+1} / Y_{t}\right), P_{t+1}=\operatorname{var}\left(\alpha_{t+1} / Y_{t}\right)
$$

The prediction error is estimated as;

$$
\begin{aligned}
& u_{t}=y_{t}-E\left(y_{t} / Y_{t-1}\right)=y_{t}-E\left(Z_{t} \alpha_{t}+\varepsilon_{t} / Y_{t-1}\right)=y_{t}-Z_{t} E\left(\alpha_{t} / Y_{t-1}\right) \\
& \quad u_{t}=y_{t}-Z_{t} a_{t}
\end{aligned}
$$


It follows that $u_{t}=Z_{t}\left(\alpha_{t}-a_{t}\right)+\varepsilon_{t}$ and $E\left(u_{t}\right)=0$, the prediction error variance is $F_{t}=\operatorname{var}\left(u_{t}\right)=Z_{t} P_{t} Z_{t}^{1}+H_{t}$.

\subsection{Local Level Model (LLM) with Seasonality}

The local level model or random walk-plus-noise model is a simple form of a linear Gaussian state space model for modelling series with little or no visible trend [3]. The model contains only the level and irregular components; the single state (level) variable follows the random walk;

$$
\begin{gathered}
y_{t}=\mu_{t}+\varepsilon_{t}, \quad \varepsilon_{t} \sim N\left(0, \sigma_{\varepsilon}^{2}\right) \\
\mu_{t}=\mu_{t-1}+\eta_{t}, \quad \eta_{t} \sim N\left(0, \sigma_{\eta}^{2}\right)
\end{gathered}
$$

where $\varepsilon_{t}$ and $\eta_{t}$ are mutually uncorrelated white-noise processes with variance $\sigma_{\varepsilon}^{2}$ and $\sigma_{\eta}^{2}$. The interpretation of this model is that $\mu_{t}$ is an (unobservable) local level or mean for the process. The observable $y_{t}$ is the underlying process mean contaminated with the measurement error $\varepsilon_{t}$. Nevertheless, when a time series are daily, monthly, or quarterly observed, it is imperative to investigate the seasonal effects in the time series. Seasonality can be handled in state space by building the seasonal effects $y_{t}$ directly into the model. Thus, adding seasonal components to equation (25) yields;

$$
\begin{aligned}
y_{t}=\mu_{t}+\gamma_{t}+\varepsilon_{t}, & \varepsilon_{t} \sim N\left(0, \sigma_{\varepsilon}^{2}\right) \\
\mu_{t}=\mu_{t-1}+\eta_{t}, & \eta_{t} \sim N\left(0, \sigma_{\eta}^{2}\right)
\end{aligned}
$$

for $t=s-1, \ldots, n$. Let $\mathrm{s}$ denote the number of 'seasons' in the data: $\mathrm{s}=12$ for monthly data; $\mathrm{s}=4$ for quarterly data; and $\mathrm{s}=7$ for daily data when modelling a weekly pattern. Since the rainfall data consists of monthly observations, the periodicity of the seasonal is $s=12$. The stochastic formulation of the seasonal effect in (27) follows from the standard dummy variable methods of modelling seasonal pattern. The effect summed over the seasons should equal zero:

$$
\gamma_{t+1}=-\sum_{j=1}^{s-1} \gamma_{t+1-j}
$$

To allow the pattern to change over time, we introduce a new disturbance term:

$$
\gamma_{t+1}=-\sum_{j=1}^{s-1} \gamma_{t+1-j}+\omega_{t}, \quad \omega_{t} \sim N\left(0, \sigma_{\omega}^{2}\right)
$$

When the seasonal effect $\gamma_{t}$ is allowed to vary over time, that is $\sigma_{\omega}^{2}$. The expectation of the sum of the seasonal effects is zero.

The Kalman filter is a statistical algorithm that enables certain computations to be carried out for a model cast in state space form [3]. However, to obtain a more accurate estimate of the state vector, the smoothing algorithm is performed. Kalman smoothing provides us with a more accurate inference on $\mu_{t}$, since it uses more 
information than the filtering [3]. Let $Y_{t-i}$ denote the set of past observations $\left\{y_{t-1}, \ldots, y_{t-i}\right\}$ and assuming the conditional distribution of $\mu_{t}$ given $Y_{t-1}$ is $N\left(\mu_{t}, p_{t}\right)$ where $\mu_{t}$ and $p_{t}$ are assumed to have been determined. Hence, the celebrated Kalman filter equations for updating the above local level model from time $\mathrm{t}$ to $\mathrm{t}+1$ are given by;

$$
\begin{gathered}
\mu_{t}=\mu_{t-1}+k_{t-1} v_{t-1}, \quad p_{t}=p_{t-1}\left(1-k_{t-1}\right)+\sigma_{\eta}^{2}, k_{t-1}=p_{t-1} / f_{t-1}, \\
v_{t-1}=y_{t-1}-\mu_{t-1}, \quad f_{t-1}=p_{t-1}+\sigma_{\varepsilon}^{2}
\end{gathered}
$$

For $t=1,2, \ldots, n$, where $v_{t-1}$ is the Kalman filter residual or prediction (signal) errors, $f_{t-1}$ is its variance and $k_{t-1}$ is the Kalman gain. A random walk like $\mu_{t-1}$ has no "natural" level and to handle the initial conditions $\left(\mu_{t}, p_{t}\right)$ for the non-stationary model, we employed the exact initial Kalman filter, [3]. The Kalman smoothed state $\hat{\mu}_{t}$ and smoothed state variance $v_{t}$ are calculated by the following backward recursions as;

$\hat{\mu}_{t}=\mu_{t}+p_{t} r_{t-1}, \quad r_{t-1}=f_{t}^{-1} v_{t}+l_{t} r_{t}, l_{t}=1-k_{t}=\sigma_{\varepsilon}^{2} / f_{t} t=n, \ldots, 1$

$v_{t}=p_{t}-p_{t}^{2} N_{t-1}, N_{t-1}=f_{t}^{-1}+l_{t}^{2} N_{t}, t=n, \ldots, 1$

The unknown variance parameters in the state space model are estimated using the maximum likelihood estimation via the Kalman filter prediction error decomposition initialized with the exact initial Kalman filter.

Diagnostic checking in this study for state space models are based on the independence and homoscedasticity assumptions concerning the residuals of the analysis. The residuals should satisfy these properties; these assumptions are checked using the following statistic.

The independence property can be checked with the Ljung-Box statistic defined as:

$$
Q_{(k)}=n(n+2) \sum_{l=1}^{k} \frac{r_{l}^{2}}{n-1} \sim \chi_{(k-N+1)}^{2}
$$

for lags $l=1, \ldots, k$. Where $r_{l}$ denotes the residual autocorrelation and is the number of hyperparameters (i.e. disturbance variances). The second most important property is the homoscedasticity of the residuals. This can be checked using the test statistic;

$$
H(h)=\frac{\sum_{t=n-h+1}^{n} \varepsilon_{t}^{2}}{\sum_{t=d+1}^{d+h} \varepsilon_{t}^{2}} \sim F(h, h)
$$

where $d$ is the number of diffuse initial elements, and $h$ is the nearest integer to $(n-d) / 3$. 


\subsection{Forecasting Evaluation Criteria}

Numerous error measures are available for forecasts evaluation; thus this study evaluates the forecasting ability of state space and Box-Jenkins type models by means of three different loss functions. These are root mean squared error (RMSE), mean absolute error (MAE) and Theil's U statistic which are defined as follows;

$$
\begin{aligned}
& \text { RMSE }=\sqrt{M S E}=\sqrt{\frac{1}{n} \sum_{t=1}^{n}\left(A_{t}-F_{t}\right)^{2}} \\
& M A E=\frac{1}{n} \sum_{t=1}^{n}\left|\left(A_{t}-F_{t}\right)\right| \\
& U_{t}=\frac{\sqrt{\sum_{t=1}^{n}\left(A_{t}-F_{t}\right)^{2}}}{\sqrt{\sum_{t=1}^{n}\left(A_{t}-A_{t-1}\right)^{2}}}
\end{aligned}
$$

where $A_{t}$ is the actual value in time $t$, and $F_{t}$ is the forecast value in time t. Theil's $\mathrm{U}$ statistic compares the forecast accuracy of different models. The overall perform of the estimating methods were accessed using the average of the three loss functions, that is Average $=\left(R M S E+M A E+U_{t}\right) / 3$, the method with the minimum Average is the best.

\section{Empirical Results}

\subsection{Data Presentation}

The nature of this study necessitated the use of secondary data and were sourced from Nigerian Meteorological Agency, Abuja. The data are monthly and generally covers the period from January 1961 to July 2019 except for FCT rainfall which ranges from January 1983 to July 2019. The estimation of the model was carried out using the EViews 9.0 Statistical package. Table 1 and 2 present the variables descriptions and summary statistics of the time series data considered in this study. Table 2 dis-plays the descriptive statistics of the series. As observed, BERF has mean, maximum and minimum of $100.81 \mathrm{~mm}, 441.00 \mathrm{~mm}$ and $0.00 \mathrm{~mm}$ respectively for the time period examined. NIRF has mean, maximum and minimum of $97.84 \mathrm{~mm}, 489.00 \mathrm{~mm}$ and $0.00 \mathrm{~mm}$ respectively for the time period examined. KORF has mean, maximum and minimum of $101.68 \mathrm{~mm}, 448.60 \mathrm{~mm}$ and $0.00 \mathrm{~mm}$ respectively for the time period examined. Furthermore, KWRF has mean, maximum and minimum of $106.49 \mathrm{~mm}$, $615.00 \mathrm{~mm}$ and $0.00 \mathrm{~mm}$ respectively for the time period examined. Also, FCRF has mean, maximum and minimum of $118.68 \mathrm{~mm}, 572.20 \mathrm{~mm}$ and $0.00 \mathrm{~mm}$ respectively for the time period examined. From the descriptive statistics (see Table 2) by means of the p-values of the variables, non-normality of the variables is confirmed at $1 \%$ level of significant (i.e. p-value $<0.01$ ). Figure 2 to 6 present the time series plots of 
Modelling Rainfall Series in North Central Nigeria: A Comparative Study of Box-Jenkins and State Space Model Approaches

the series.

Table 1: Variables Description

\begin{tabular}{l|l|l|l}
\hline \multicolumn{1}{c|}{ Variables } & Code & SARIMA Model & State Space Model \\
\hline Benue Rainfall & BERF & SBER & SSBER \\
Niger Rainfall & NIRF & SNIR & SSNIR \\
Kogi Rainfall & KORF & SKOR & SSKOR \\
Kwara Rainfall & KWRF & SKWR & SSKWR \\
FCT Rainfall & FCRF & SFCR & SSFCR \\
\hline
\end{tabular}

Source: Researchers' codes

Table 2: Descriptive Statistics

\begin{tabular}{l|c|c|c|c|c}
\hline & BERF & NIRF & KORF & KWRF & FCRF \\
\hline Mean & 100.81 & 97.84 & 101.68 & 106.49 & 118.68 \\
\hline Median & 83.00 & 61.20 & 86.50 & 85.90 & 100.70 \\
\hline Maximum & 441.00 & 489.00 & 448.60 & 615.00 & 572.20 \\
\hline Minimum & 0.00 & 0.00 & 0.00 & 0.00 & 0.00 \\
\hline Std. Dev. & 103.08 & 108.51 & 99.98 & 106.00 & 121.04 \\
\hline Skewness & 0.82 & 0.89 & 0.76 & 1.03 & 0.88 \\
\hline Kurtosis & 2.86 & 2.89 & 2.88 & 3.97 & 3.21 \\
\hline Jarque-Bera & 80.28 & 92.48 & 68.04 & 151.15 & 57.69 \\
\hline P-value & 0.00 & 0.00 & 0.00 & 0.00 & 0.00 \\
\hline Observations & 703 & 703 & 703 & 703 & 439 \\
\hline \multicolumn{2}{l}{ Source: Researchers' computations } & & &
\end{tabular}

The figures (i.e. Figure 2 to Figure 6; see Appendix) reveal evidence that stationary features are clearly inherent in BERF, NIRF, KORF, KWRF and FCRF rainfall series. Furthermore, from figures BERF, NIRF, KORF, KWRF and FCRF series fluctuate over the years with highest spike in August 1987, September 2010, August 1971, May 2016 and August 1994 respectively.

\subsection{Test for Non-seasonal and Seasonal Stationarity}

Conventionally, we utilized the augmented Dickey-Fuller (ADF) test to examine the non-seasonal stationarity of the series [4]. Table 3 presents the non-seasonal stationarity test results for the rainfall series. The ADF results depict p-values less than 0.01 for all the rainfall series. Hence, just as shown in Figure 2 to 6 , the ADF test concedes non-seasonal stationarity at level for all the rainfall series. Subsequently, the series are investigated for seasonal stationarity using HEGY (Hylleberg-Engle-Granger-Yoo) test. Table 4 presents the seasonal stationarity test results. The HEGY statistics show that for all the rainfall series considered, the seasonal stationarity null hypothesis can be rejected in all the frequencies. The HEGY results further show that all the series are trend stationary and contained significant seasonal drifts in the monthly seasonal components. Hence there is no need of non-seasonal differencing $(\mathrm{d}=0)$ and seasonal differencing $(\mathrm{D}=0)$. 
Table 3: ADF Test

\begin{tabular}{llcll}
\hline Variables & $\widehat{k}$ & Integration Order $(\boldsymbol{d})$ & Test Stat & P-Value \\
\hline BERF & 12 & 0 & -6.044 & $0.000^{*}$ \\
NIRF & 12 & 0 & -5.350 & $0.000^{*}$ \\
KORF & 11 & 0 & -6.124 & $0.000^{*}$ \\
KWRF & 11 & 0 & -4.165 & $0.001^{*}$ \\
FCRF & 11 & 0 & -4.006 & $0.002^{*}$ \\
\hline
\end{tabular}

Note: $\widehat{k}$ is the AIC lag term is used to select the optimal lag, to make the residuals white noise and * denotes significant at $1 \%$ level. Source: Researchers' computations

Table 4: HEGY Test

\begin{tabular}{c|ccccc}
\hline Null & BERF & NIRF & KORF & KWRF & FCRF \\
\hline Nonseasonal unit root (Zero frequency) & $-7.6693^{*}$ & $-6.5172^{*}$ & $-7.3541^{*}$ & $-5.6644^{*}$ & $-5.3613^{*}$ \\
Seasonal unit root (2 months per cycle) & $-6.1588^{*}$ & $-8.0450^{*}$ & $-6.8038^{*}$ & $-7.3125^{*}$ & $-6.5932^{*}$ \\
Seasonal unit root (4 months per cycle) & $59.1211^{*}$ & $51.3380^{*}$ & $54.8099^{*}$ & $50.3360^{*}$ & $31.9547^{*}$ \\
Seasonal unit root (2.4 months per cycle) & $43.2323^{*}$ & $58.8887^{*}$ & $40.7100^{*}$ & $66.0569^{*}$ & $32.4482^{*}$ \\
Seasonal unit root (12 months per cycle) & $58.7169^{*}$ & $51.8106^{*}$ & $60.3599^{*}$ & $43.2091^{*}$ & $30.4923^{*}$ \\
Seasonal unit root (3 months per cycle) & $53.1373^{*}$ & $47.2231^{*}$ & $45.0274^{*}$ & $59.2103^{*}$ & $26.2831^{*}$ \\
Seasonal unit root (6 months per cycle) & $52.5801^{*}$ & $52.5683^{*}$ & $61.5923^{*}$ & $55.7009^{*}$ & $29.5986^{*}$ \\
\hline \hline
\end{tabular}

Note: * denotes significant at $1 \%$ level.

Source: Researchers' computations

\subsection{Estimation of SARIMA Models}

In this context, model building commences with the examination of the plots of the stationary series and seasonally attuned series (see Figure 2 to 6). Figure 7 to 11 present the correlogram of the series. The PACFs in Figure 6 to 10 provides evidence of seasonality in the rainfall series. The ACFs exhibit oscillatory movements of period 12 months. From a close observation of the correlograms i.e. plots of ACF and PACF (see Figure 7 to 11), we noticed that both the ACFs and PACFs displayed significant spikes and exponential decrement. Hence, they signify ARMA processes and the displayed significant spikes at lag12 of PACFs indicate seasonality of the series. We used the behaviors of the autocorrelations and partial autocorrelations displayed in figure 7 to 11 to identify some candidate models which are further subjected to model selection analysis to obtain the most parsimonious SARIMA models for all the rainfall series.

Based on these outlines, the Automatic ARIMA forecasting in EViews was used to select the best SARIMA models among other candidate models using ARMA Maximum Likelihood (BFGS) method. It automatically considered several ARMA models, then choose the one which its residuals are independent with the lowest AIC. Table 5 presents the summary of the estimated SARIMA models with the highest likelihood function, smallest standard error of estimate and the minimum AIC (see Figure 12 to 16 in the appendix) among all the ARIMA structures considered. Based on these important statistics highlighted, the SARIMA models presented in Table 5 
Modelling Rainfall Series in North Central Nigeria: A Comparative Study of Box-Jenkins and State Space Model Approaches

provides the best satisfactory fit to the rainfall series. Furthermore, the DurbinWatson (DW) statistic indicates the models' residuals do not suffer from autocorrelation (since DW is approximately 2 ; see the appendix for the details of these best SARIMA models selected).

Table 5: Summary of SARIMA Models Estimated

\begin{tabular}{|c|c|l|l|l|c|}
\hline $\begin{array}{c}\text { Rainfall } \\
\text { Series }\end{array}$ & $\begin{array}{l}\text { No. of Estimated } \\
\text { ARMA Models }\end{array}$ & $\begin{array}{l}\text { Selected } \\
\text { SARIMA } \\
\text { Model }\end{array}$ & $\begin{array}{l}\text { AIC } \\
\text { value }\end{array}$ & $\begin{array}{l}\text { Standard Error ( ) } \\
\text { Likelihood [ ] }\end{array}$ & $\begin{array}{l}\text { Durbin } \\
\text { Watson (DW) } \\
\text { value }\end{array}$ \\
\hline BERF & 225 & $(4,0,4)(1,0,0)_{12}$ & 11.1412 & $(62.4804)[-3799.30]$ & 1.9217 \\
\hline NIRF & 144 & $(3,0,3)(2,0,0)_{12}$ & 11.1032 & $(60.7154)[-3320.95]$ & 2.0786 \\
\hline KORF & 64 & $(2,0,3)(1,0,0)_{12}$ & 11.0670 & $(60.3325)[-3776.92]$ & 2.0138 \\
\hline KWRF & 225 & $(2,0,4)(1,0,0)_{12}$ & 11.0226 & $(56.9036)[-3294.77]$ & 1.9834 \\
\hline FCRF & 225 & $(4,0,2)(2,0,0)_{12}$ & 11.2339 & $(64.7371)[-2349.13]$ & 1.9850 \\
\hline
\end{tabular}

\subsection{Estimation of State Space Models}

The subsamples i.e. 1961:1-1979:12, 1980:1-1998:12 and 1999:1-2017:12 for BERF, NIRF, KORF and KWRF while 1983:1-1995:2, 1995:3-2007:4 and 2007:5-2019:6 for FCRF, means and variance are not equal over time, which is an indication that the subsample means and variance are not constant. For example, the subsample means are BERF; 102.72, 99.75 \& 100.04, NIRF; 99.81, 93.36 \& 98.59, KORF; 100.84, $98.63 \& 105.90$, KWRF; 101.18, 99.56 \& 114.84 and FCRF; 122.68, $121.45 \&$ 111.76. Hence, the means varies across the samples. Thus, the state space model that accommodates non-stationary features by representing the level of the series as a random walk process, since random walk process is non-stationary, would be appropriate for modelling the series [3].

The choice of components to be contained within state space models are based on the characteristics of the observed series. Since seasonality is customarily presented in a monthly time series data, we utilized the Local Level Model (LLM) with Seasonality described in methodology section for all the series. The unknown parameters for the variances and the unobserved component are therefore estimated using the maximum likelihood (Marquardt) method of estimation. This is maximized using the BFGS (Broyden-Fletcher-Goldfarb-Shannon) optimization method because the BFGS approximates the Newton's method and has proven to have good performance even for non-smooth optimizations, [3] and Lewis \& Overton, 2008). The estimation results for the local level model with seasonality are presented in Table 6 to 10 . 
Table 6: State Space Estimation of BERF

\begin{tabular}{|c|c|c|c|c|}
\hline \multicolumn{5}{|c|}{$\begin{array}{l}\text { Method: Maximum likelihood (BFGS / Marquardt steps) } \\
\text { Sample: 1961M01 2017M12 } \\
\text { Included observations: } 684 \\
\text { Convergence achieved after } 60 \text { iterations } \\
\text { Coefficient covariance computed using outer product of gradients }\end{array}$} \\
\hline & Coefficient & Std. Error & z-Statistic & Prob. \\
\hline $\mathrm{C}(1)$ & 2.270200 & 0.077758 & 119.2189 & 0.0000 \\
\hline $\mathrm{C}(2)$ & -11.24331 & 56095.55 & -0.000200 & 0.9998 \\
\hline \multirow[t]{2}{*}{$\mathrm{C}(3)$} & 0.061117 & 2390.488 & $2.56 \mathrm{E}-05$ & 0.0000 \\
\hline & Final State & Root MSE & z-Statistic & Prob. \\
\hline SV1 & 101.0172 & 3.943666 & 25.61505 & 0.0000 \\
\hline SV3 & -1311.812 & 1232.414 & -1.064424 & 0.2871 \\
\hline Log likelihood & -5294.839 & Akaike info criterion & & 15.49076 \\
\hline Parameters & 3 & Schwarz criterion & & 15.51062 \\
\hline Diffuse priors & 2 & Hannan-Quinn criter. & & 15.49844 \\
\hline
\end{tabular}

Source: EViews9 outputs

Table 6 to Table 9 show that the state space models had been fitted on 684 observations. In Table 6, state space model was fitted for BERF using the Marquardt optimization algorithm taking 60 iterations to achieve convergence solution. At convergence, the maximum of the log likelihood is found to be -5294.839 . The coefficients $\mathrm{C}(1)=2.2902, \mathrm{C}(2)=-11.2433$ and $\mathrm{C}(3)=0.0611$ are the logs of the variances of the error terms for the measurement and state equations respectively, i.e. $\sigma_{\varepsilon}^{2}=9.8769, \sigma_{\eta}^{2}=0.000013$, and $\sigma_{\omega}^{2}=1.0630$. Furthermore, the coefficients of measurement for $\sigma_{\varepsilon}^{2}$, and $\sigma_{\omega}^{2}$ are significant at $1 \%$ level which denotes the significance of $\sigma_{\varepsilon}^{2}$ and $\sigma_{\omega}^{2}$. The final state of the unobserved component for one-step ahead and two-step predicted values are 101.0172 and -1311.812 respectively.

The Root Mean Square Error (RMSE) which is the metric of comparison for the forecasting ability of the model is smaller in the Kalman Filter for the SV1 (3.9437) indicating robustness in the one-step ahead forecast than two-steps ahead (SV3). Hence, one-step ahead method of forecast is suitable for the series BERF.

In Table 7, the state space model was fitted for NIRF using the Marquardt optimization algorithm taking 117 iterations to achieve convergence solution. At convergence, the maximum of the log likelihood is found to be -5242.202 . The coefficients $\mathrm{C}(1)=1.2042, \mathrm{C}(2)=2.8109$ and $\mathrm{C}(3)=-11.9020$ are the logs of the variances of the error terms for the measurement and state equations respectively i.e. $\sigma_{\varepsilon}^{2}=3.3341 \sigma_{\eta}^{2}=16.6249$ and $\sigma_{\omega}^{2}=6.78 \mathrm{E}-6$. Furthermore, the coefficients of measurement for $\sigma_{\varepsilon}^{2}$ and $\sigma_{\eta}^{2}$ i.e. $\mathrm{C}(1)$ and $\mathrm{C}(2)$ respectively are significant at $1 \%$ which denotes the significant of $\sigma_{\varepsilon}^{2}$ and $\sigma_{\eta}^{2}$. The final state of the unobserved 
Modelling Rainfall Series in North Central Nigeria: A Comparative Study of Box-Jenkins and State Space Model Approaches

component for one-step ahead and two-step predicted values are 23.4640 and 299.1105 .

The RMSE which is the metric of comparison for the forecasting ability of the model is smaller in the Kalman Filter for the SV1 (126.1208) indicating robustness in the one-step ahead forecast than two-steps ahead (SV3). Hence, one-step ahead method of forecast is suitable for the series NIRF.

Table 7: State Space Estimation of NIRF

\begin{tabular}{|c|c|c|c|c|}
\hline \multicolumn{5}{|c|}{$\begin{array}{l}\text { Method: Maximum likelihood (BFGS / Marquardt steps) } \\
\text { Sample: 1961M01 2017M12 } \\
\text { Included observations: } 684 \\
\text { Convergence achieved after } 117 \text { iterations } \\
\text { Coefficient covariance computed using outer product of gradients }\end{array}$} \\
\hline & Coefficient & Std. Error & z-Statistic & Prob. \\
\hline $\mathrm{C}(1)$ & 1.204214 & 0.220364 & 32.69232 & 0.0000 \\
\hline $\mathrm{C}(2)$ & 2.810866 & 0.109351 & 80.57391 & 0.0000 \\
\hline \multirow[t]{2}{*}{ C (3) } & -11.90197 & $2.87 \mathrm{E}+08$ & $-4.14 \mathrm{E}-08$ & 0.9989 \\
\hline & Final State & Root MSE & z-Statistic & Prob. \\
\hline SV1 & 23.46401 & 126.1208 & 0.186044 & 0.8524 \\
\hline SV3 & -299.1105 & 1244.343 & -0.240376 & 0.8100 \\
\hline Log likelihood & -5242.202 & Akaike info criterion & & 15.33685 \\
\hline Parameters & 3 & Schwarz criterion & & 15.35671 \\
\hline Diffuse priors & 2 & Hannan-Quinn criter. & & 15.34453 \\
\hline
\end{tabular}

Source: EViews9 outputs

Table 8: State Space Estimation of KORF

\begin{tabular}{|c|c|c|c|c|}
\hline \multicolumn{5}{|c|}{$\begin{array}{l}\text { Method: Maximum likelihood (BFGS / Marquardt steps) } \\
\text { Sample: 1961M01 2017M12 } \\
\text { Included observations: } 684 \\
\text { Convergence achieved after } 47 \text { iterations } \\
\text { Coefficient covariance computed using outer product of gradients }\end{array}$} \\
\hline & Coefficient & Std. Error & z-Statistic & Prob. \\
\hline $\mathrm{C}(1)$ & 3.332092 & 0.193177 & 37.95530 & 0.0000 \\
\hline $\mathrm{C}(2)$ & 4.060431 & 0.109853 & 78.83689 & 0.0000 \\
\hline \multirow[t]{2}{*}{$\mathrm{C}(3)$} & $7.02 \mathrm{E}-05$ & 1910.654 & 3.67E-08 & 0.0899 \\
\hline & Final State & Root MSE & z-Statistic & Prob. \\
\hline SV1 & 27.18557 & 118.1214 & 0.230149 & 0.0880 \\
\hline SV3 & -348.8579 & 1196.277 & -0.291620 & 0.7706 \\
\hline Log likelihood & -5217.227 & Akaike info criterion & & 15.26382 \\
\hline Parameters & 3 & Schwarz criterion & & 15.28368 \\
\hline Diffuse priors & 2 & Hannan-Quinn criter. & & 15.27151 \\
\hline
\end{tabular}

Source: EViews9 outputs 
Table 8 depicts that convergence was achieved at 47 iterations. At convergence, the maximum of the log likelihood is found to be -5217.227 . The coefficients $\mathrm{C}(1)=$ $3.3321, \mathrm{C}(2)=4.6604$ and $\mathrm{C}(3)=7.02 \mathrm{E}-05$ are the logs of the variances of the error terms for the measurement and state equations respectively, hence $\sigma_{\varepsilon}^{2}=27.9971$, $\sigma_{\eta}^{2}=57.9975$, and $\sigma_{\omega}^{2}=1.0000$. Furthermore, the coefficient of measurement for $\sigma_{\varepsilon}^{2}, \sigma_{\eta}^{2}$ and $\sigma_{\omega}^{2}$ are significant at $1 \%$ which denotes the significant of $\sigma_{\varepsilon}^{2}, \sigma_{\eta}^{2}$ and $\sigma_{\omega}^{2}$ The final state of the unobserved component for one-step ahead and two-step predicted values are 27.1856 and -348.8579. The RMSE which is the metric of comparison for the forecasting ability of the model is smaller in the Kalman Filter for the SV1 (118.1214) indicating robustness in the one-step ahead forecast than twosteps ahead (SV3). Hence, one-step ahead method of forecast is suitable for the series KORF.

Table 9: State Space Estimation of KWRF

Method: Maximum likelihood (BFGS / Marquardt steps)

Sample: 1961M01 2017M12

Included observations: 684

Convergence achieved after 84 iterations

Coefficient covariance computed using outer product of gradients

\begin{tabular}{|c|c|c|c|c|}
\hline & Coefficient & Std. Error & z-Statistic & Prob. \\
\hline $\mathrm{C}(1)$ & 2.168229 & 0.071721 & 127.8316 & 0.0000 \\
\hline $\mathrm{C}(2)$ & 1.423919 & 0.687441 & 2.071331 & 0.0383 \\
\hline \multirow[t]{2}{*}{$\mathrm{C}(3)$} & 2.707402 & 0.711752 & 12.23376 & 0.0000 \\
\hline & Final State & Root MSE & z-Statistic & Prob. \\
\hline SV1 & 156.8457 & 14.69818 & 10.67109 & 0.0000 \\
\hline SV3 & -2043.359 & 1188.068 & -1.719900 & 0.0855 \\
\hline Log likelihood & -5291.865 & Akaike info criterion & & 15.48206 \\
\hline Parameters & 3 & Schwarz criterion & & 15.50192 \\
\hline Diffuse priors & 2 & Hannan-Quinn criter. & & 15.48975 \\
\hline
\end{tabular}

Table 10: State Space Estimation of FCRF

Method: Maximum likelihood (BFGS / Marquardt steps)

Sample: 1983M01 2017M12

Included observations: 420

Convergence achieved after 58 iterations

Coefficient covariance computed using outer product of gradients

\begin{tabular}{ccccc}
\hline \hline & Coefficient & Std. Error & z-Statistic & Prob. \\
\hline \hline C (1) & 2.304810 & 2.024209 & 2.620682 & 0.0088 \\
C (2) & 3.163565 & 0.111396 & 82.26150 & 0.0000 \\
C (3) & 0.121211 & 2320.247 & $5.22 \mathrm{E}-05$ & 0.9999 \\
\hline \hline & Final State & Root MSE & z-Statistic & \multirow{2}{*}{ Prob. } \\
\hline \hline SV1 & 6.470347 & 145.5816 & 0.044445 & 0.0645 \\
SV3 & 341.6868 & 1308.396 & 0.261149 & 0.7940 \\
\hline \hline
\end{tabular}


Modelling Rainfall Series in North Central Nigeria: A Comparative Study of Box-Jenkins and State Space Model Approaches

\begin{tabular}{lrlr} 
Log likelihood & -3239.648 & Akaike info criterion & 15.44118 \\
Parameters & 3 & Schwarz criterion & 15.47004 \\
Diffuse priors & 2 & Hannan-Quinn criter. & 15.45259 \\
\hline
\end{tabular}

Source: EViews9 outputs

Table 10 displays that state space model was fitted on 420 observations the model using the Marquardt optimization algorithm taking 58 iterations to achieve convergence solution. At convergence, the maximum of the log likelihood is found to be -3239.648 . The coefficients $\mathrm{C}(1)=2.3048, \mathrm{C}(2)=3.1636$ and $\mathrm{C}(3)=0.1212$ are the logs of the variances of the error terms for the measurement and state equations respectively i.e. $\sigma_{\varepsilon}^{2}=10.0222, \sigma_{\eta}^{2}=23.6556$ and $\sigma_{\omega}^{2}=1.1289$. Furthermore, the coefficients of measurement for $\sigma_{\varepsilon}^{2}$ and $\sigma_{\eta}^{2}$ i.e. $\mathrm{C}(1)$ and $\mathrm{C}(2)$ respectively are significant at $5 \%$ which denotes the significant of $\sigma_{\varepsilon}^{2}$ and $\sigma_{\eta}^{2}$. The final state of the unobserved component for one-step ahead and two-step ahead predicted values are 6.4703 and 341.6868 respectively. The RMSE which is the metric of comparison for the forecasting ability of the model is smaller in the Kalman Filter for the SV1 (145.5816) indicating robustness in the one-step ahead forecast than two-steps ahead (SV3). Hence, one-step ahead method of forecast is suitable for the series FCRF. The Kalman Filter output (smoothed state estimates), actual, predicted and std. residuals of the rainfall series are presented in Figure 17 to 26 (see appendix).

\subsubsection{State Space Models Diagnosis}

In order to diagnose the goodness of fit of the state space models for the various series, the Q-statistics and homoscedasticity of residuals in each particular case are considered, the result of which is presented in Table 11. From the diagnosis of the models for the various series data presented in Table 11, the models appear appropriate for the data at the $99 \%$ confidence level because the Q-statistics and heteroscedasticity show that there is no statistically significant trace of dependency and no heteroscedasticity left in the residual indicating that the mean equation and variance equation are adequately specified.

Table 11: State Space Models Diagnosis

\begin{tabular}{|l|c|c|}
\hline & Q(p-value) & H-test (p-value) \\
\hline SSBER & $0.0975(0.9999)$ & $7.03 E-05(0.9933)$ \\
\hline SSNIR & $0.0021(0.999)$ & $1.5864(0.1184)$ \\
\hline SSKOR & $15.642(0.739)$ & $1.6502(0.1994)$ \\
\hline SSKWR & $0.0047(0.998)$ & $1.3967(0.1289)$ \\
\hline SSFCR & $0.0482(0.998)$ & $0.9491(0.2232)$ \\
\hline
\end{tabular}

Source: Researchers' computations 


\subsection{Forecasting Evaluation}

The SARIMA and state space models are estimated based on the monthly data from 1961:1 to 2017:12, and ex post forecasts are generated for the time period 2018:1 to 2019:7. The plot of the actual rainfall values for 2018:1 to 2019:07 versus the SARIMA and state space models forecasts are depicted in Figure 27 to 31 (see appendix). The forecast analyses clearly show that the state space models forecast clearly outperform the Box-Jenkins models in Figure 27 to 32. To determine the performance of the fitted models in forecasting future rainfall pattern root mean square error (RMSE), mean absolute error (MAE) and Theil's U criteria of the forecast sample rainfall are compared. This result is presented in Table 12.

The forecasting ability of the state space models are examined with respect to the best fitting SARIMA models. From the forecasts evaluation results presented in Table 12, the minimum RMSE, MAE, and Theil's U indicate that the state space local level models with seasonality outperform the Box-Jenkins models. Hence, state space model is more appropriate to model and forecast Benue, Niger, Kogi, Kwara and Federal Capital Territory (FCT) rainfall series.

Table 12: Forecasting Evaluation Criteria

\begin{tabular}{ll|cccc} 
Source: & Forecast & RMSE & MAE & Theil's U & Average \\
\cline { 2 - 6 } & SBER & 51.2096 & 36.9253 & 0.167742 & 29.4342 \\
SSBER & $\mathbf{2 8 . 5 8 4 1}$ & $\mathbf{2 1 . 1 4 0 2}$ & $\mathbf{0 . 0 9 2 7 0 9}$ & $\mathbf{1 6 . 6 0 5 6 8}$ \\
\hline SNIR & 109.987 & 81.1725 & 0.291302 & 63.81708 \\
SSNIR & $\mathbf{3 3 . 8 9 4 8}$ & $\mathbf{2 6 . 8 9 5}$ & $\mathbf{0 . 0 7 5 4 8 9}$ & 20.28843 \\
\hline SKOR & 75.1844 & 56.4172 & 0.236324 & 43.94596 \\
SSKOR & $\mathbf{1 . 0 8 E - 0 5}$ & $\mathbf{6 . 3 6 E - 0 6}$ & $\mathbf{3 . 1 0 E - 0 8}$ & $\mathbf{5 . 7 3 E - 0 6}$ \\
\hline SKWR & 132.798 & 88.8775 & 0.318756 & 73.99809 \\
SSKWR & $\mathbf{5 1 . 2 4 1 3}$ & $\mathbf{3 4 . 9 7 9 6}$ & $\mathbf{0 . 1 0 1 7 4 7}$ & $\mathbf{2 8 . 7 7 4 2}$ \\
\hline SFCR & 82.6227 & 61.8943 & 0.274526 & 48.26383 \\
SSFCR & $\mathbf{3 . 0 6 5 9 9}$ & $\mathbf{2 . 3 1 9 0 1}$ & $\mathbf{0 . 0 1 2 3 4 3}$ & $\mathbf{1 . 7 9 9 1 1 2}$ \\
\hline
\end{tabular}

\section{Conclusions}

This paper fits suitable state space and Box-Jenkins models to rainfall series of five states in North Central of Nigeria and compared the forecasting performances of the fitted models. Prior to the forecasting comparison, the study employed state space model; Local Level Model (LLM) with Seasonality to model the dynamic features in the rainfall series. All the state space models estimated for the rainfall of five states passed the diagnostic tests for the residuals. Additionally, appropriate SARIMA models were also fit to the rainfall series after subjecting the series to ADF and HEGY 
Modelling Rainfall Series in North Central Nigeria: A Comparative Study of Box-Jenkins and State Space Model Approaches

tests. Thus, $\quad \operatorname{SARIMA}(4,0,4)(1,0,0)_{12}, \quad \operatorname{SARIMA}(3,0,3)(2,0,0)_{12}$, $\operatorname{SARIMA}(2,0,3)(1,0,0)_{12}, \quad \operatorname{SARIMA}(2,0,4)(1,0,0)_{12}$ and $\operatorname{SARIMA}(4,0,2)(2,0,0)_{12}$ returned as the most parsimonious BJ models for Benue, Niger, Kogi, Kwara and Federal Capital Territory (FCT) states respectively. The forecast evaluation of the state space and most parsimonious SARIMA models was assessed using the RMSE, MAE, and Theil's U criteria. The minimum RMSE, MAE, and Theil's U indicate that the state space local level model with seasonality outperform the Box-Jenkins models for the five-rainfall series examined. In conclusion, state space model returned as more robust model compare to the most parsimonious Box-Jenkins model (SARIMA). Hence, the study recommends the adoption of state space modelling approach counter to Box-Jenkins modelling approach based on the ability of the approach to accommodate distinct features instead of differencing (i.e. eliminating trend and seasonality). Furthermore, although not exploited in this study, in practical applications for specification of forecast ranges practitioners should also consider the forecasting horizons.

\section{References}

[1] Afrifa-Yamoah E., Bashiru I. I. S. and Azumah K. (2016). SARIMA Modelling and Forecasting of Monthly Rainfall in the Brong Ahafo Region of Ghana. World Environment. 6(1): 1-9.

[2] Akpenpuun T. D and Busari R. A, (2013). Impact of Climate on Tuber Crops Yield in Kwara State, Nigeria. American International Journal of Contemporary Research, 3(10).

[3] Asemota O. J. (2016). State Space Versus SARIMA Modeling of the Nigeria's Crude Oil Export. Sri Lankan Journal of Applied Statistics, 17(2).

[4] Asemota, O. J. and Adejumo, O. A. (2017). Structural Breaks and Unit Root in Macroeconomic Time Series: Evidence from Nigeria. Sri Lankan Journal of Applied Statistics. 18(1), pp.35-47.

[5] Burton A., Kilsby C.G., Fowler H.J., Cowpertwait P.S.P., and O'Connell P.E. (2008). A spatial-temporal stochastic rainfall modeling system. Environment Modeling \& Software 23, 1356-1369.

[6] Chisimkwuo J., Uchechukwu G. and Okezie, S. C. (2016). Time series analysis and forecasting of monthly maximum temperatures in south eastern Nigeria. International Journal of Innovative Research and Development-Natural Hazards, 81 (3), 1811-1827.

[7] Commandeur J. J. F., Koopman S. J. and Ooms M. (2011). Statistical Software for State Space Methods. Journal of Statistical Software, 41(1). 
[8] Doguwa, S. I. and Alade, S. O. (2015). On Time Series Modeling of Nigeria's External Reserves, CBN Journal of Applied Statistics, 6(1), 1 - 28.

[9] Durbin, J. and Koopman, S. (2001). Time Series Analysis by State Space Methods. Oxford University Press.

[10] Easterling W. E. (1997). Why regional studies are needed in the development of full-scale integrated assessment modelling of global change processes. Global Environmental Change, 7(4), 337-356.

[11] Elias, K., Jalal Behzadi, M., Taher, N., Alireza, G. and Mohammad Ali D. (2012). Modeling ARIMA of air temperature of the southern Caspian Sea coasts. International Research Journal of Applied and Basic Sciences, 3 (6), 1279-128.

[12] Ette, H. E. and Mohamed, T. M. (2014). Time Series Analysis of Monthly Rainfall data for the Gadaref rainfall station, Sudan, by Sarima Methods. International Journal of Scientific Research in Knowledge 2(7), 320-327.

[13] Hasanean H. M. (2001). Fluctuations of Surface Air Temperature in the Eastern Mediterranean. Theoretical and Applied Climatology. 68, 75-87.

[14] Hylleberg, S., Engle, R. F., Granger, C. W. J., and Yoo, B. S., (1990). Seasonal integration and cointegration. Journal of Econometrics, 44, 215-238.

[15] IPCC (2007). Climate Change 2007. Synthesis Report, Contribution of Working Groups I, II, \& III to the Fourth Assessment Report of the Interogovernmental Panel on Climate Change. Geneva.http://D0/10.1017/CB09780511546013.

[16] Hazarika, J., Pathak, B. and Patowary, A. N. (2017). Studying monthly rainfall over Dibrugarh, Assam: Use of SARIMA approach. MAUSAM, 68(2), 349-356.

[17] Kalman R. E. (1960) A new approach to linear filtering and prediction problems. Transactions of the ASME. Journal of Basic Engineering, 82:35-45.

[18] Karl T.R., Jones P.D., Knight R.W., Kukla G., Plummer N., Razuvayev V., Gallo K.P., Lindesay J., Charlson R.J. and Peterson T.C. (1993). Asymetric trends of daily maximun and minimum temperature. Bull. Amer. Meteor. Soc. 74, 1007-1023

[19] Koller, D. and Friedman, N. (2009). Probabilistic Graphical Models. Cambridge, MA: MIT Press.

[20] Murat, M., Malinowska, I., Gos, M. and Krzyszczak, J. (2018). Forecasting daily meteorological time series using ARIMA and regression models. International Agrophysics 32, 253-264

[21] Shafaei, M., Adamowski, J., Fakheri-Fard, A., Dinpashoh, Y. and Adamowski, K. (2016). A wavelet-SARIMA-ANN hybrid model for precipitation forecasting. Journal of Water and Land Development, 28 27-36 
Modelling Rainfall Series in North Central Nigeria: A Comparative Study of Box-Jenkins and State Space Model Approaches

[22] Nirmala M., and Sundaram S. M. (2010). A Seasonal ARIMA Model for Forecasting Monthly Rainfall in Tamilnadu. National Journal on Advances in Building Sciences and Mechanics, 2 (43).

[23] Odekunle, T. O. (2001). The magnitude - Frequency Characteristic of Rainfall in Ondo, Southwestern Nigeria. Ife Research Publications in Geography, 8, 36 -41 .

[24] Olanrewaju, R. M., (2009). Climate and the Growth Cycle of Yam Plant in the Guinea Savannah Ecological Zone of Kwara State, Nigeria. Journal of Meteorological and Climate Science, 7, 43-48.

[25] Ologunorisa, E. T. (2001). An Assessment of Flood Risk in the Niger Delta, Nigeria. Unpublished Ph. D

[26] Ologunorisa, E. T. (2004). Rainfall Flood Prediction in the Niger Delta, Nigeria (Abstract), International Conference in Hydrology: Science and Practice for the $21^{\text {st }}$ Century, London, U.K.

[27] Rabiner, L. R. (1989) A tutorial on hidden Markov models and selected applications in speech recognition. Proceedings of the IEEE, 77(2): 257-286

[28] Salau, M. O. (1998). Arima Modelling of Nigeria's Crude Oil Exports, AMSE, Modelling, Measurement \& Control, 18(1), 1-20.

[29] UNFCCC (2011). Framework Convention on Climate Change. Ad hoc Working Group on Further Commitments for Annex 1 Parties under the Kyoto Protocol Sixteenth session, part four Durban.

[30] Wagener T., Mclntyre N., Lees M. J., Wheater H. S., and Gupta H.V. (2003). Towards reduced uncertainty in conceptual rainfall-runoff modeling: Dynamic identifiability analysis. Hydological Processes, 17, 455-476.

[31] Chen, Z. and Brown, E. N. (2013). State Space Model. Scholarpedia, 8(3):30868

[32] United Nations (2019). Climate Change Summit 2019.

http://www.un.org/en/climatechange/ 


\section{Appendix}

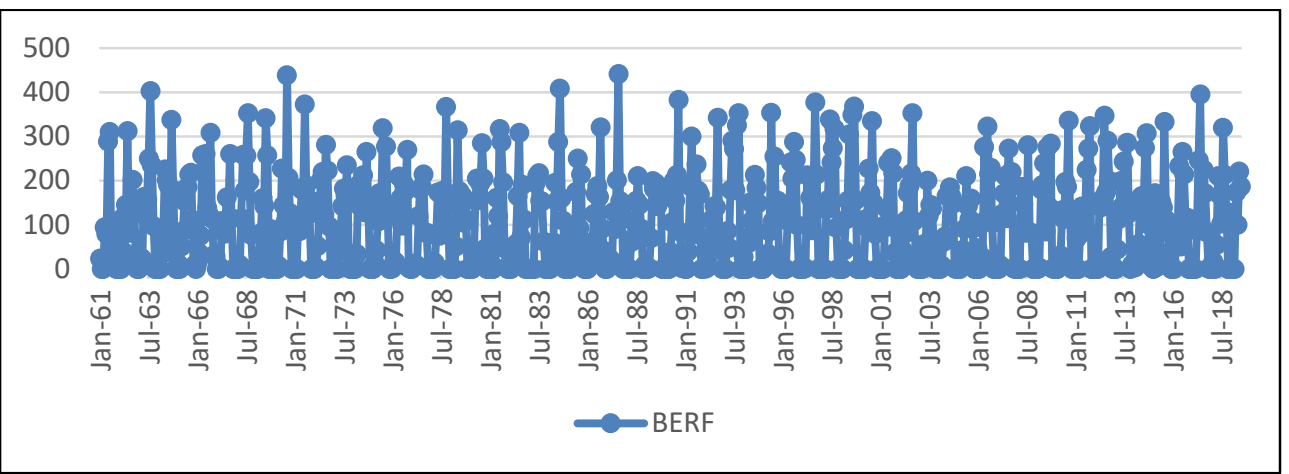

Figure 2: Time Series Plot of Makurdi Rainfall (Benue)

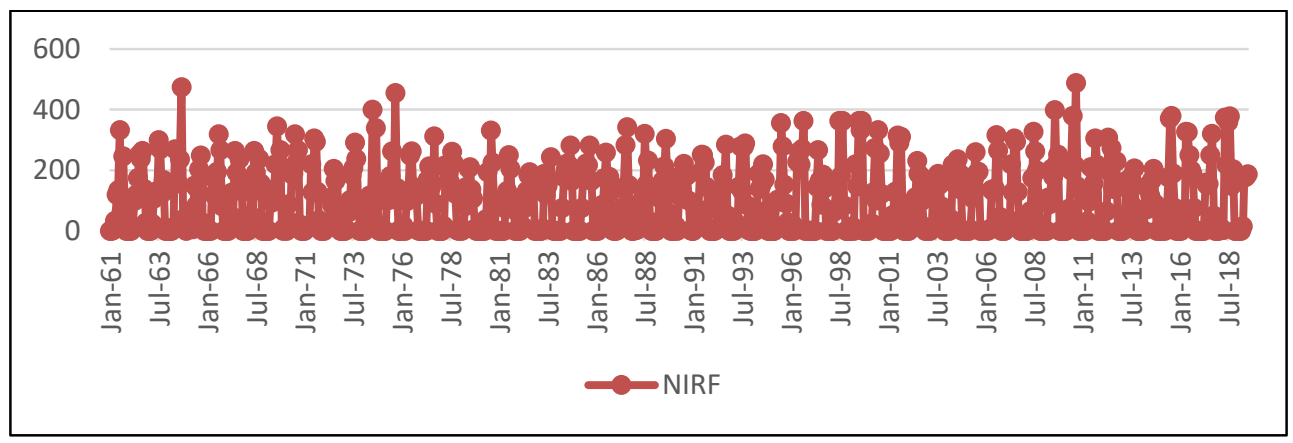

Figure 3: Time Series Plot of Bida Rainfall (Niger)

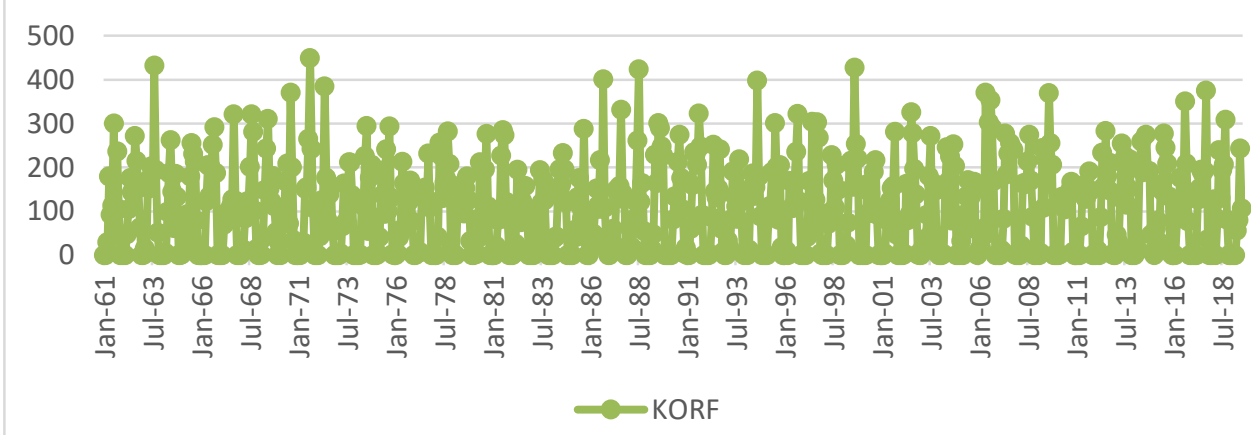

Figure 4: Time Series Plot of Lokoja Rainfall (Kogi) 
Modelling Rainfall Series in North Central Nigeria: A Comparative Study of Box-Jenkins and State Space Model Approaches

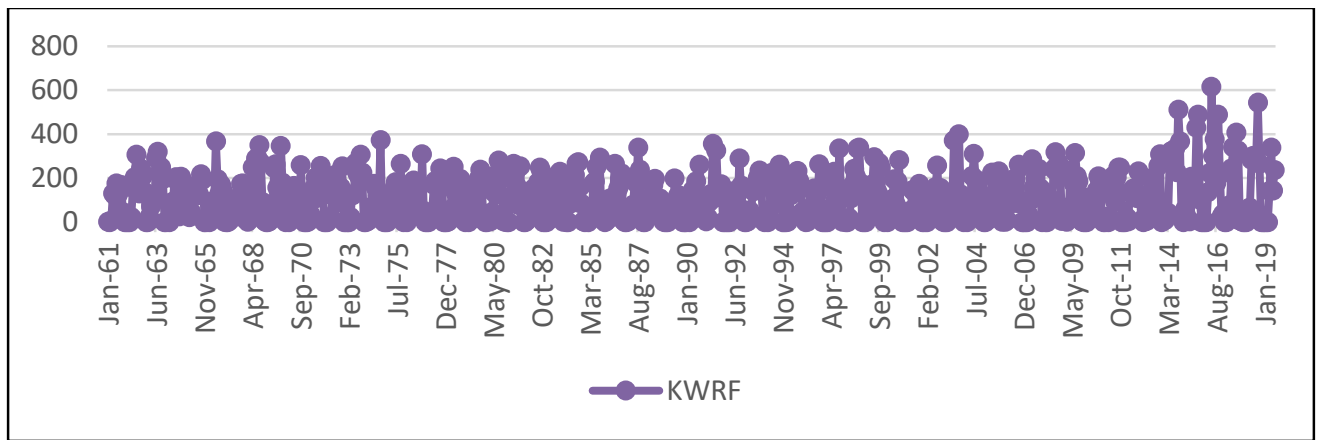

Figure 5: Time Series Plot of Ilorin Rainfall (Kwara)

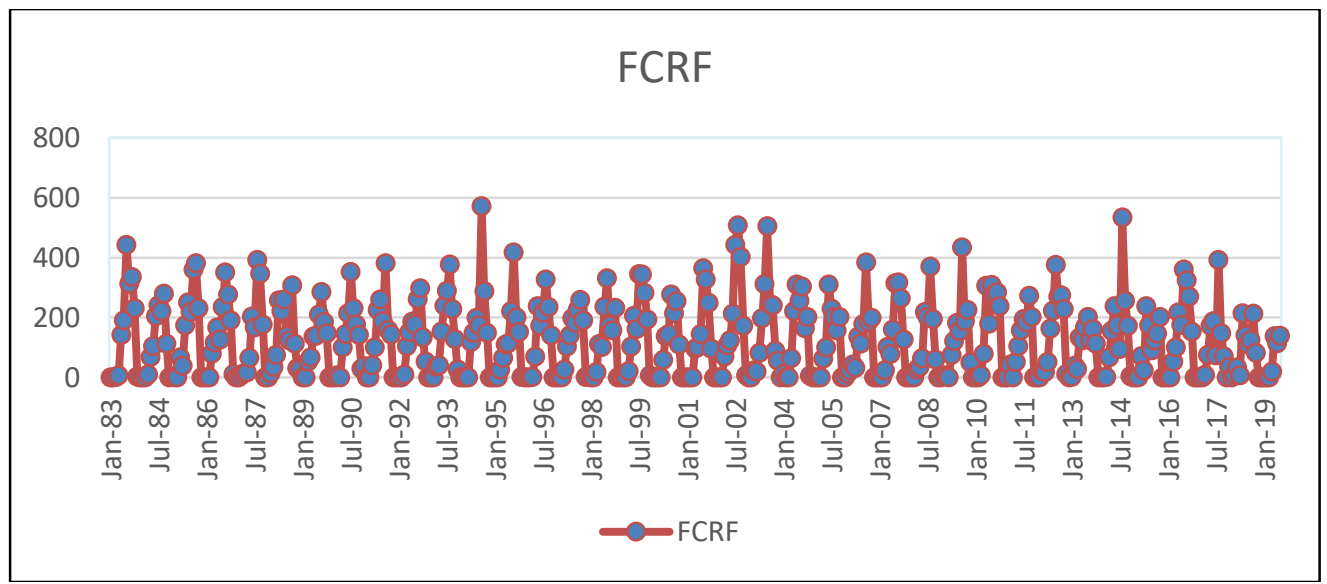

Figure 6: Time Series Plot of Abuja Rainfall (FCT)

\begin{tabular}{|c|c|c|c|c|c|}
\hline Adscentishon & Pasaicontidsto & $A C$ & PAC & Q-Stat & Poos \\
\hline 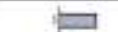 & $\Rightarrow$ & 1.5546 & $05 \%$ & 200.9 & 0000 \\
\hline 曰 & $\sqrt{1}$ & 20271 & 0000 & $202 . \mathrm{Aa}$ & 0000 \\
\hline 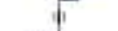 & E & 34023 & 022 & 20285 & 0000 \\
\hline 문 & G & $4-9230$ & -0.267 & 32234 & 0.000 \\
\hline$\exists$ & 目 & 54515 & -0359 & 52569 & 0.000 \\
\hline 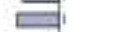 & 回 & 6. 4.228 & .0344 & $\cos 35$ & 0000 \\
\hline 四 & a & 7.4525 & $\rightarrow 189$ & 1012.9 & 0.000 \\
\hline 日 & 1. & $A-291$ & 0.070 & 10590 & 0000 \\
\hline a & d & 0.4030 & 0001 & $10 \pm 67$ & 0600 \\
\hline 尸 & 3 & $10 \quad 4272$ & 0065 & 11124 & 0.000 \\
\hline E & a & it 0.544 & 0195 & 13241 & 0.000 \\
\hline 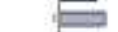 & 泊 & $12 \quad 0.672$ & 0.51 & 16477 & 0000 \\
\hline$\Xi$ & ip & $13 \quad 0.519$ & 0069 & 18409 & $0 \times 0$ \\
\hline 田 & is & 14 1221 & $000 \mathrm{~s}$ & 18979 & 0000 \\
\hline$\sqrt{1}$ & $\zeta$ & 15.0094 & 0005 & 18ท9 & 0000 \\
\hline 四 & d & $16-1236$ & -0064 & 19513 & 0000 \\
\hline$\exists$ & di & 174514 & 0005 & $2+52.3$ & 0.000 \\
\hline$\Rightarrow$ & di & $18-4532$ & -144 & 2412 & 0000 \\
\hline 반 & 7. & $19-4525$ & -0.073 & 2640.7 & 0000 \\
\hline 口 & it & 204235 & 0000 & 26391 & 0000 \\
\hline
\end{tabular}

Figure 7: BERF Correlogram

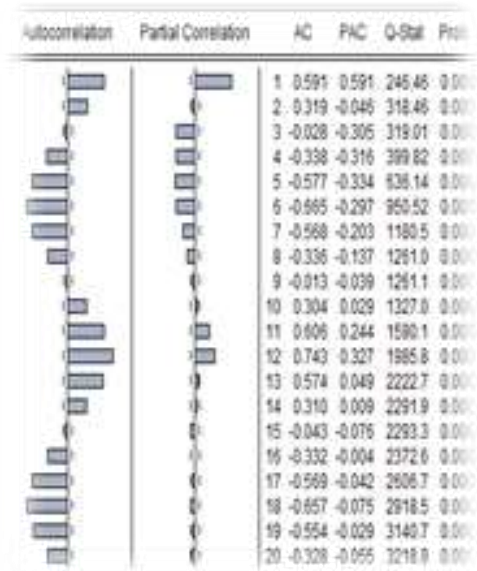

Figure 8: NIRF Correlogram 


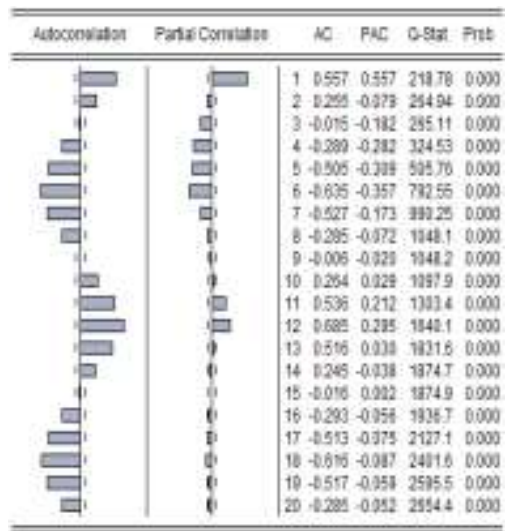

Figure 9: KORF Correlogram

\begin{tabular}{|c|c|c|c|c|c|}
\hline Abtereisen & Psts Contstan & K & $F E$ & osex & An \\
\hline$\equiv$ & 口 & 10304 & 0534 & 19422 & Docos \\
\hline 它 & 8 & 20268 & -0067 & 2241 & 0000 \\
\hline i) & b & 30040 & 0012 & 2215 & 0000 \\
\hline E. & 도 & $4-2,17$ & 0216 & 233 & 0.000 \\
\hline$\square$ & 回 & 5.0414 & -0.314 & $375 \mathrm{ES}$ & ocee \\
\hline$\square$ & 다 & 1.0 .50 & 0210 & 60041 & ooces \\
\hline 달 & 6 & 7.0004 & $-0,078$ & 6665 & 000 \\
\hline di & it & 10,010 & atts. & $\cos \mathrm{s}$ & 0000 \\
\hline it & ) & 10000 & 0063 & 660.17 & acke \\
\hline 邑 & ) & it 0 tos & 0045 & 71224 & 0000 \\
\hline פ & 白 & 11.0 .073 & 0238 & BTJ $4 t$ & 0000 \\
\hline$=$ & 日 & 120.637 & 0301 & t1tat & $0,0 e$ \\
\hline 巴 & 4 & 13. 0.42 & 0604 & 1311? & 0000 \\
\hline ip & d & 14.0 .168 & Q 18 & 18016 & 0006 \\
\hline i) & ) & 18. 0008 & 0043 & $133 t:$ & 0000 \\
\hline 달 & $\theta$ & $18-0,177$ & 0004 & 13625 & 0006 \\
\hline 무 & 6 & $17-0,360$ & -0005 & 14EXI & 0000 \\
\hline$\Xi$ & 6 & It 0.021 & soces & 10254 & 0000 \\
\hline 말 & 1 & $14-0 \times 3$ & Q07e & 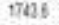 & 0006 \\
\hline 마 & 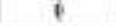 & 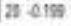 & .0062 & 1722 & acee \\
\hline
\end{tabular}

Figure 10: KWRF Correlogram

Akaike Information Criteria (top 20 models)

\begin{tabular}{|c|c|c|c|c|c|}
\hline Whtantatin & Patad Conutidon. & Ne & skt & 2sit & Ant \\
\hline$\square$ & $\square$ & 10669 & 1976 & 1552 & oxs \\
\hline 0 & Ei & 20343 & มाt! & 24.18 & oode \\
\hline+ & 댄. & 3.0097 & 230 & zas & 000 \\
\hline 且 & 당 & 40354 & $122 \%$ & 347 & $000 \mathrm{~s}$ \\
\hline & \# & 5.654 & 228 & 46730 & 2000 \\
\hline$\square$ & 당 & 1 Q Q5A & 2301 & Bate & 0000 \\
\hline$\square$ & t) & $T$ tost & 186 & 8128 & oode \\
\hline 미 & 2 & 8.692 & 114 & 6495 & oove \\
\hline+ & ip & 80017 & 228 & $\operatorname{sen} \theta$ & Q6ee \\
\hline$p$ & ) & to 0321 & $20 \%$ & N5553 & Qoos \\
\hline$\square$ & 旧 & HI 0622 & 226 & 11244 & 2000 \\
\hline 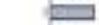 & in & 12.070 & 2213 & 1329 & 2006 \\
\hline$=$ & 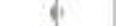 & 13 0St5 & 4006 & 1521 & 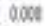 \\
\hline$\square$ & I & 4.0313 & 2794 & $1525 \%$ & 000 \\
\hline (? & d) & 15.0344 & 201 & $1 \mathrm{tan} 6$ & 000 \\
\hline 미 & it & 160387 & 2048 & 1059 & ooces \\
\hline & d & it ass & $-2 \% 3$ & 11353 & 000 \\
\hline$\square$ & d & 18.0642 & $-20 \% 8$ & 28425 & 000 \\
\hline$\square$ & (1) & 140.025 & 4247 & 27381 & dowt \\
\hline 四 & (1) & (2) 035 & 400 & 2047 & 0000 \\
\hline
\end{tabular}

Figure 11: FCRF Correlogram

Akaike Information Criteria (top 20 models)

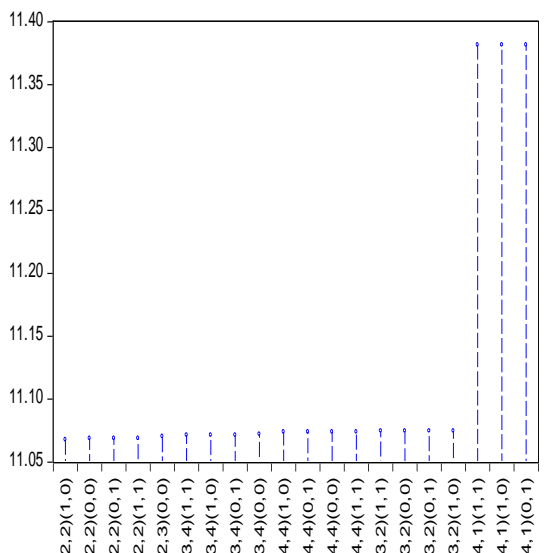

Figure 13: AIC Plot of NIRF Top Models

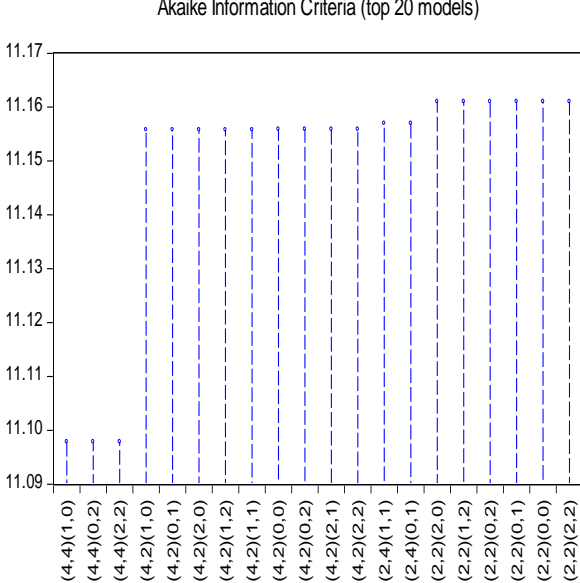

Figure 12: AIC Plot of BERF Top Models Akaike Information Criteria (top 20 models)

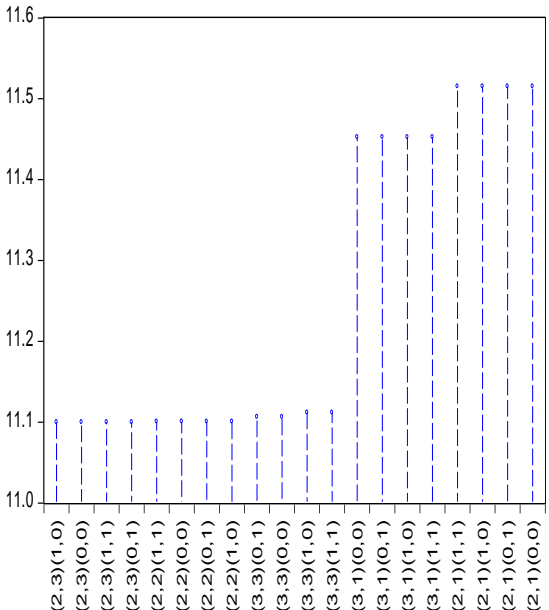

a a n a m m m m m m m m a d a

Figure 14: AIC Plot of KORF Top Models 
Modelling Rainfall Series in North Central Nigeria: A Comparative Study of Box-Jenkins and State Space Model Approaches
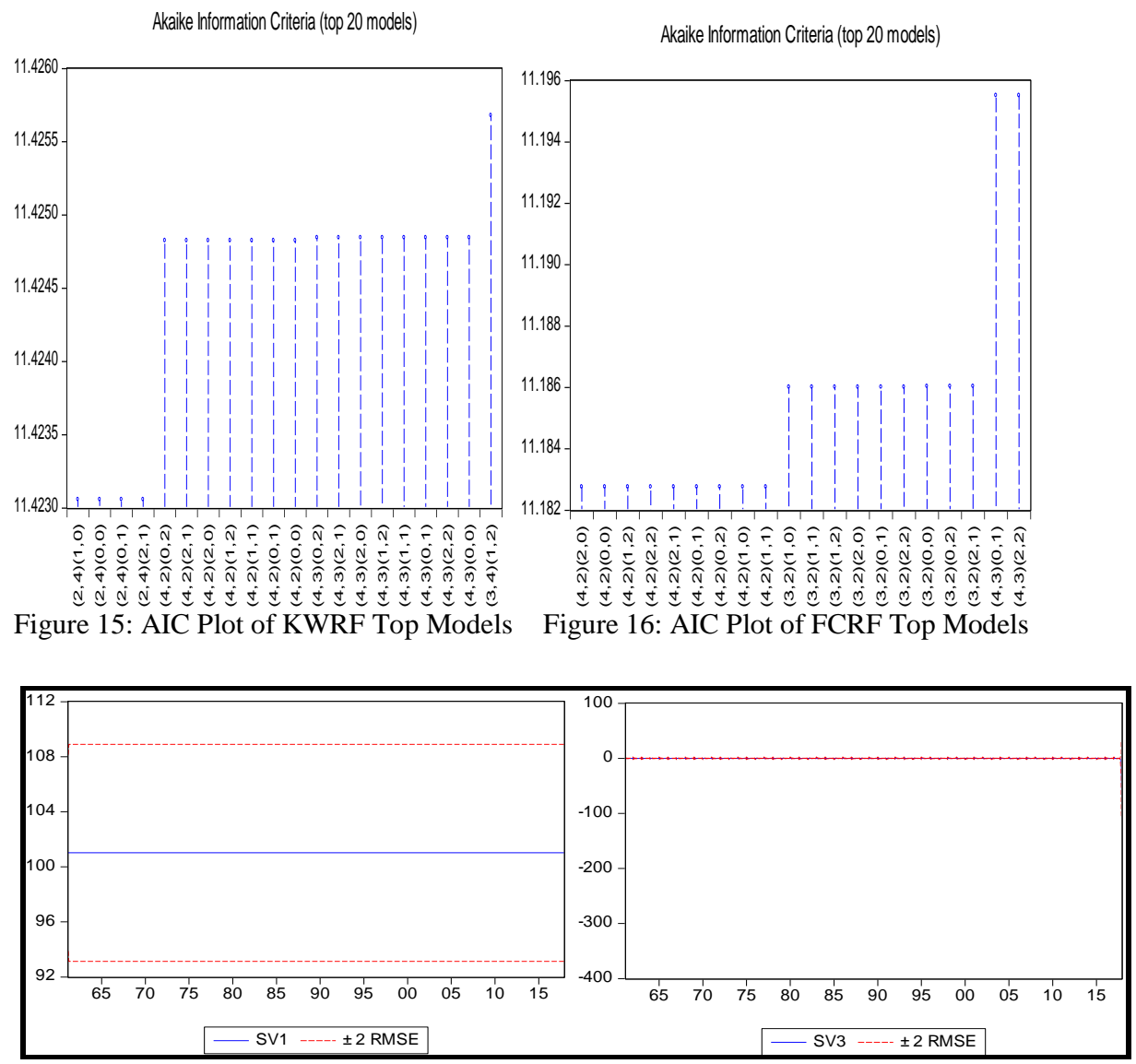

Figure 17: Smoothed State Estimates (BERF)

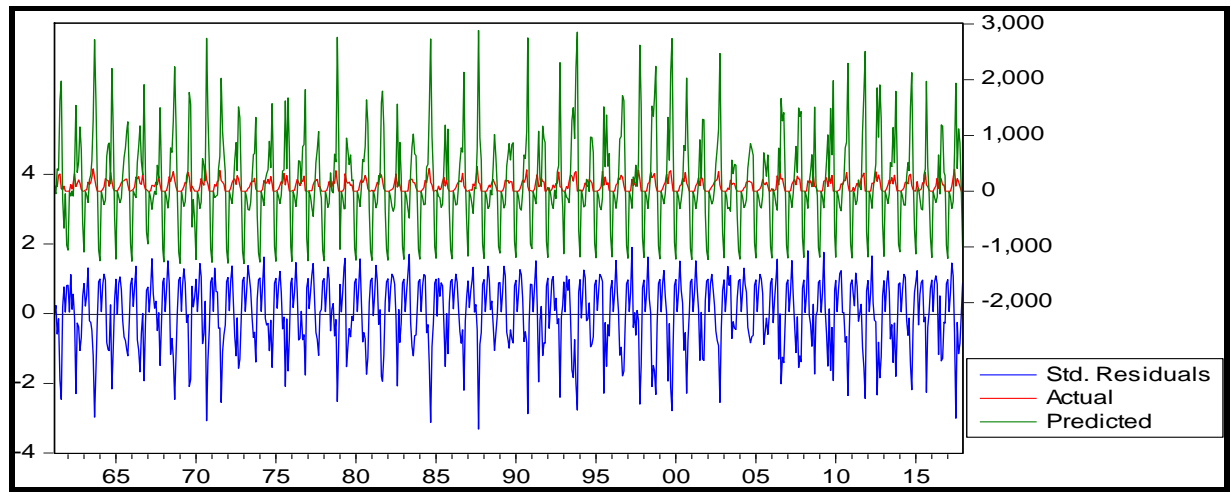

Figure 18: Actual, Predicted and Std. Residual (One-step-ahead BERF) 


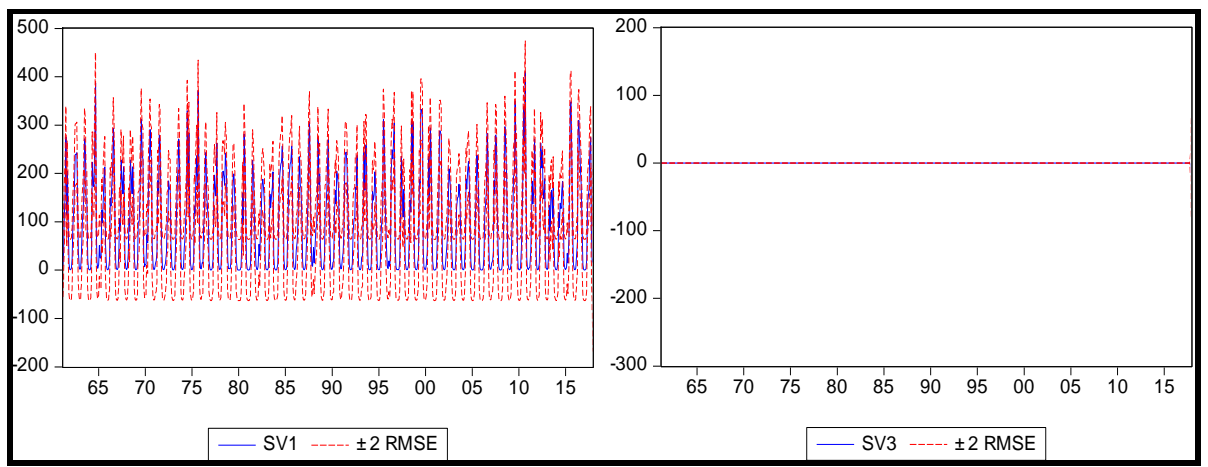

Figure 19: Smoothed State Estimates (NIRF)

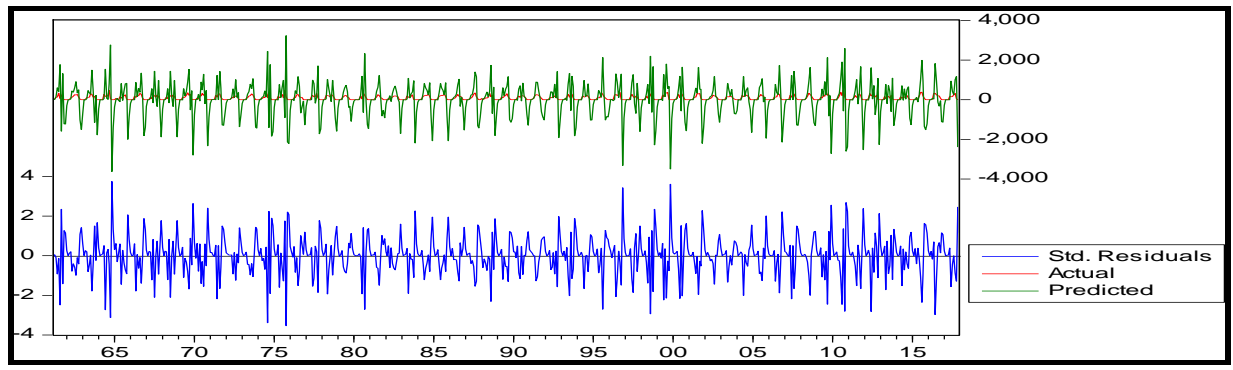

Figure 20: Actual, Predicted and Std. Residual (One-step-ahead NIRF)

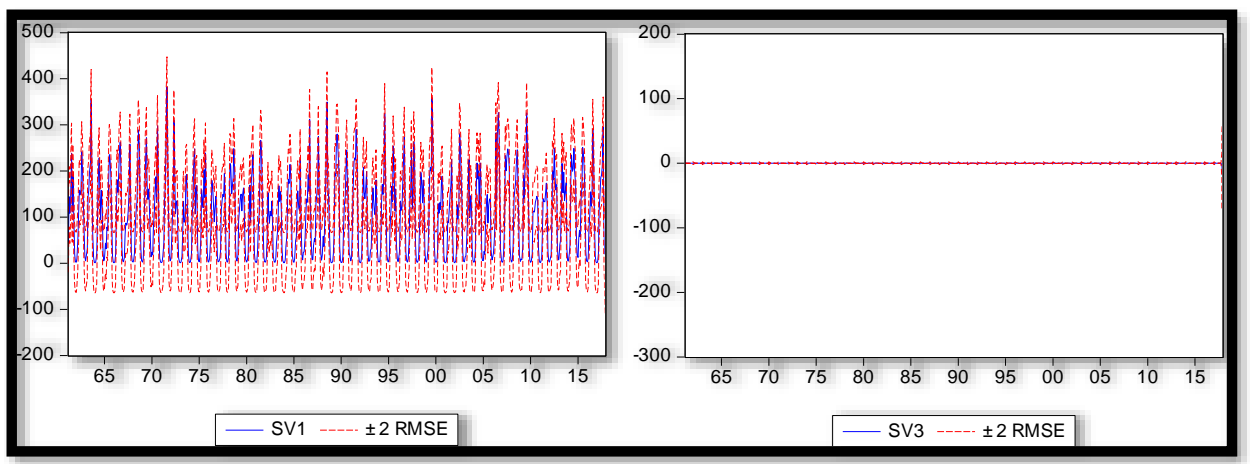

Figure 21: Smoothed State Estimates (KORF)

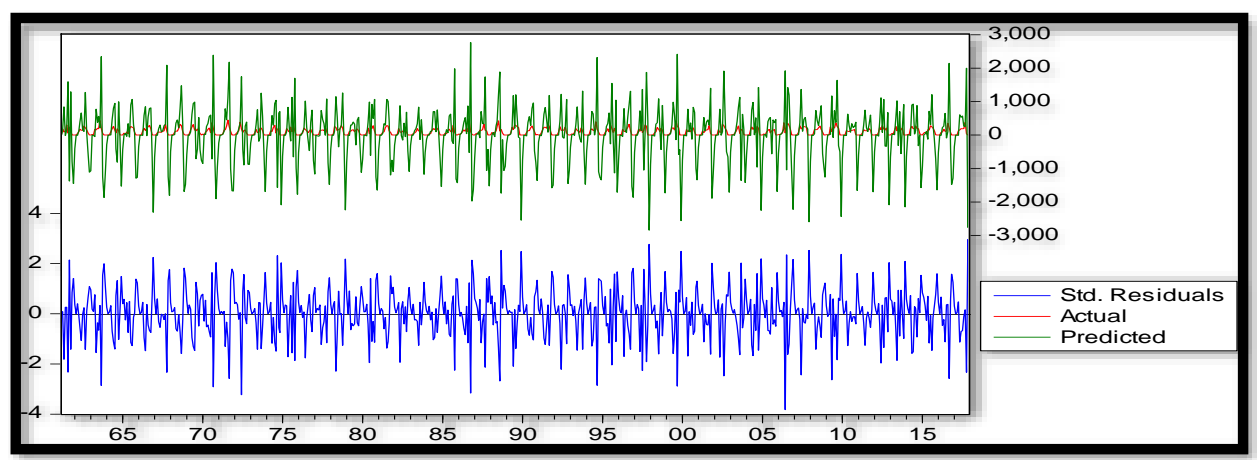

IASSL 
Modelling Rainfall Series in North Central Nigeria: A Comparative Study of Box-Jenkins and State Space Model Approaches

Figure 22: Actual, Predicted and Std. Residual (One-step-ahead KORF)

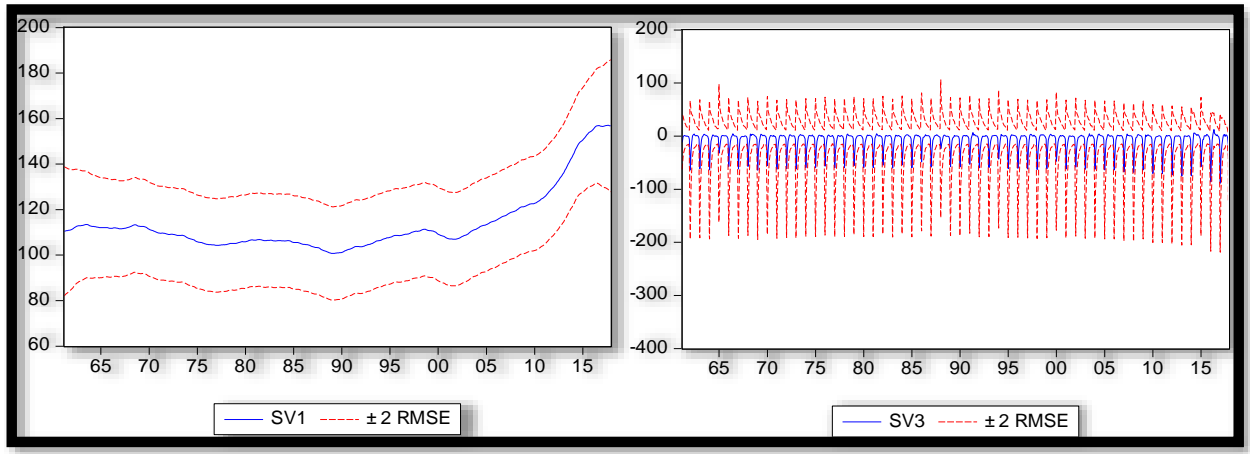

Figure 23: Smoothed State Estimates (KWRF)

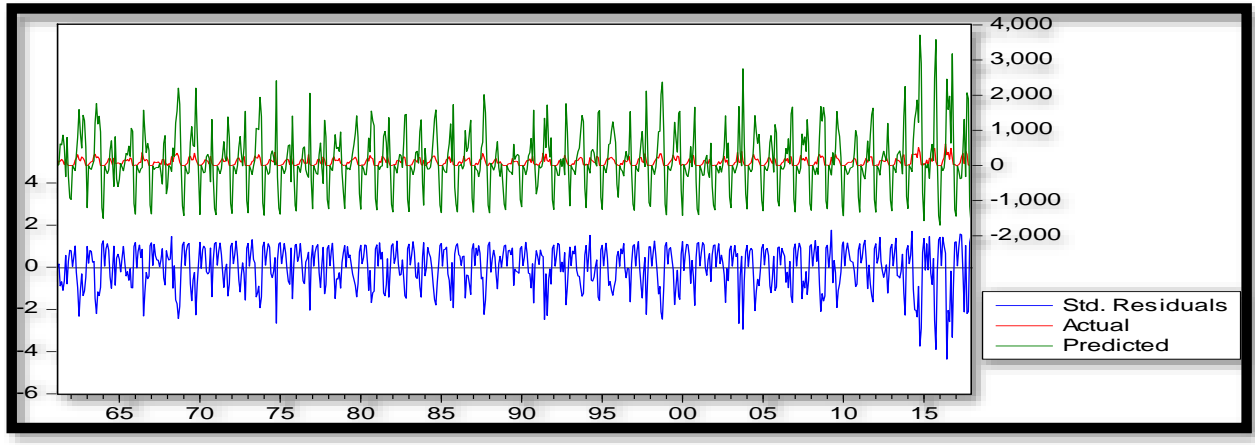

Figure 24: Actual, Predicted and Std. Residual (One-step-ahead KWRF)

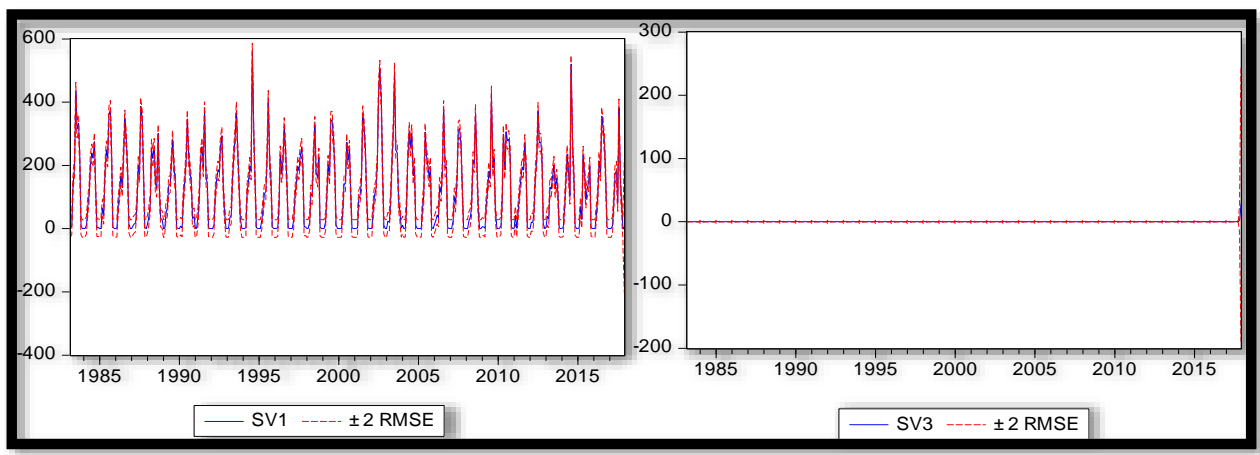

Figure 25: Smoothed State Estimates (FCRF) 


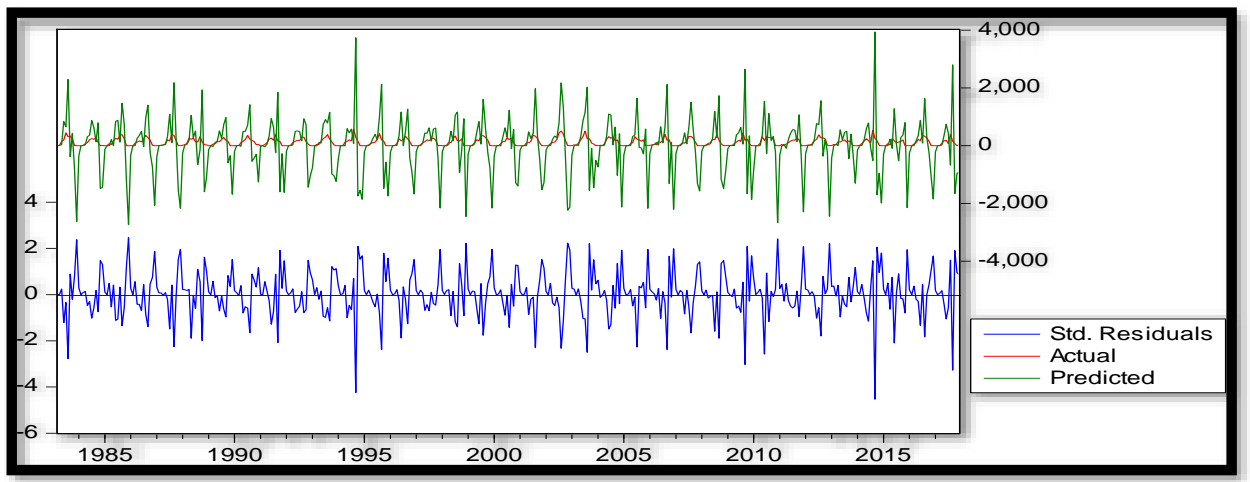

Figure 26: Actual, Predicted and Std. Residual (One-step-ahead FCRF)

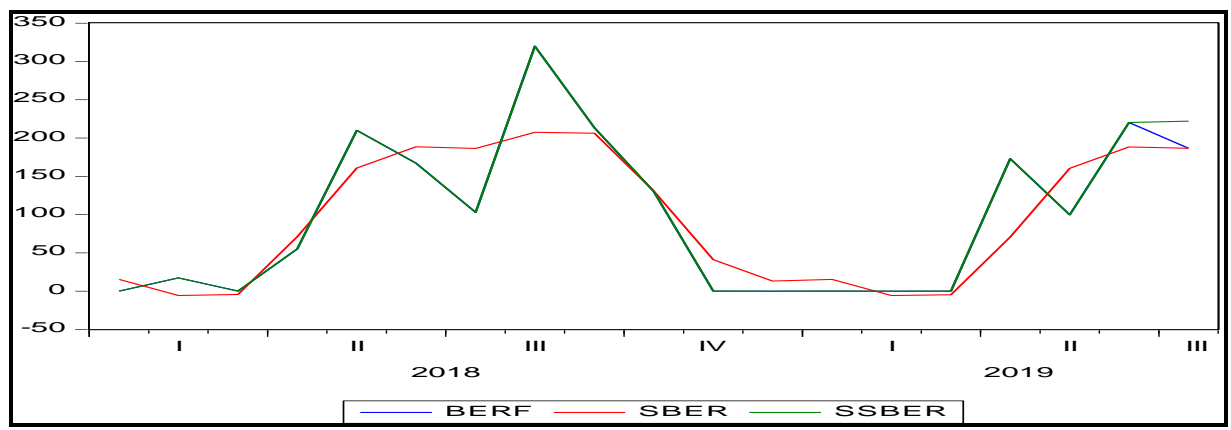

Figure 27: Actual values, Box-Jenkins and State Space Models Forecasts (BERF)

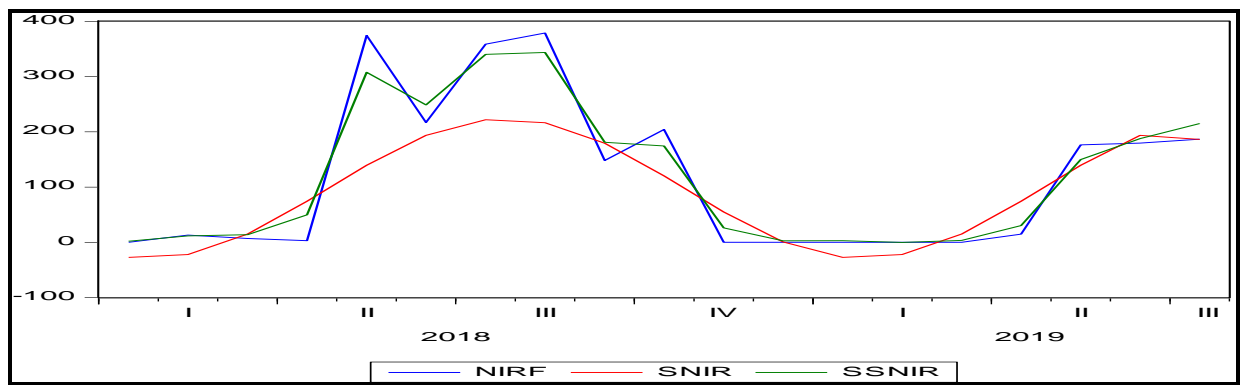

Figure 28: Actual values, Box-Jenkins and State Space Models Forecasts (NIRF)

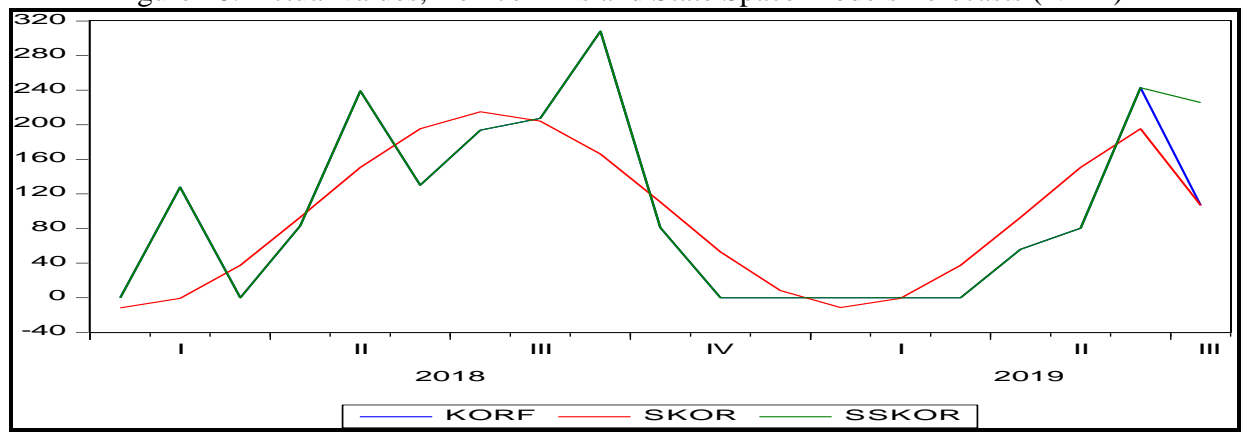

Figure 29: Actual values, Box-Jenkins and State Space Models Forecasts (KORF) 
Modelling Rainfall Series in North Central Nigeria: A Comparative Study of Box-Jenkins and State Space Model Approaches
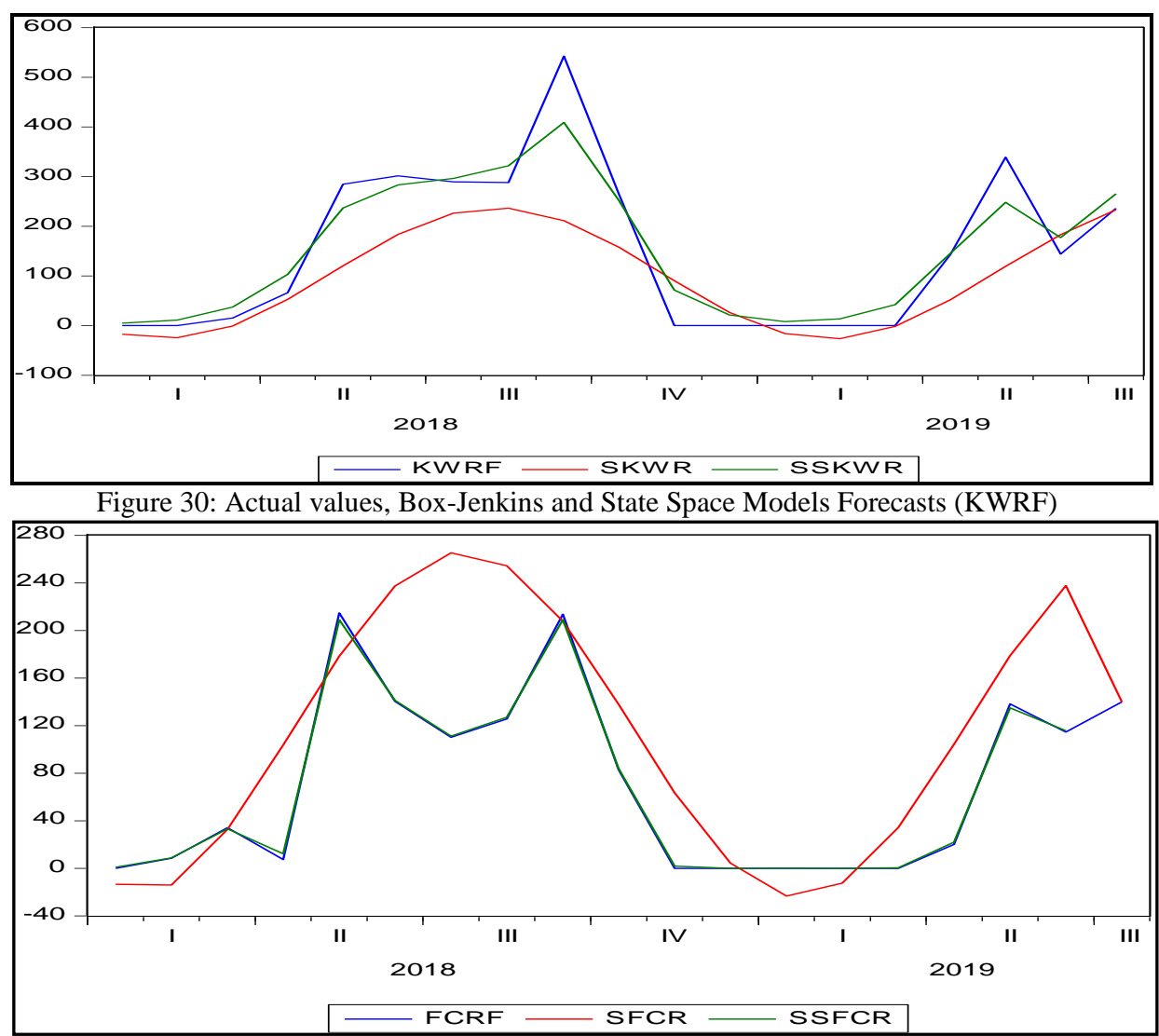

Figure 31: Actual values, Box-Jenkins and State Space Models Forecasts (FCRF) 